TID-4500, UC-4

Chemistry

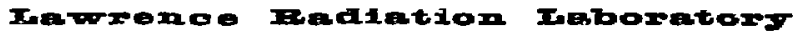

QIIUESITY of CAIfGRHA

LIVERUORE

94550

UCRL-51043

\title{
ESTIMATION OF HEAT CAPACITIES AND OTHER THERMODYNAMIC PROPERTIES OF REFRACTORY BORIDES
}

Oscar H. Krikorian

Tht tepart wh prepared as in eccount of woth This tepar we Unifed Strtes Government. Ketther the United States nor the United Strta Momic Enew

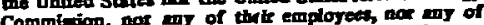
Comminion, was eng or the

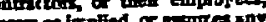

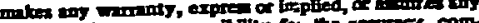

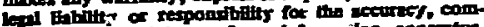

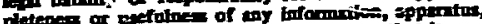

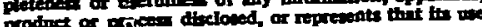

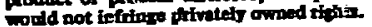




\section{Contents}

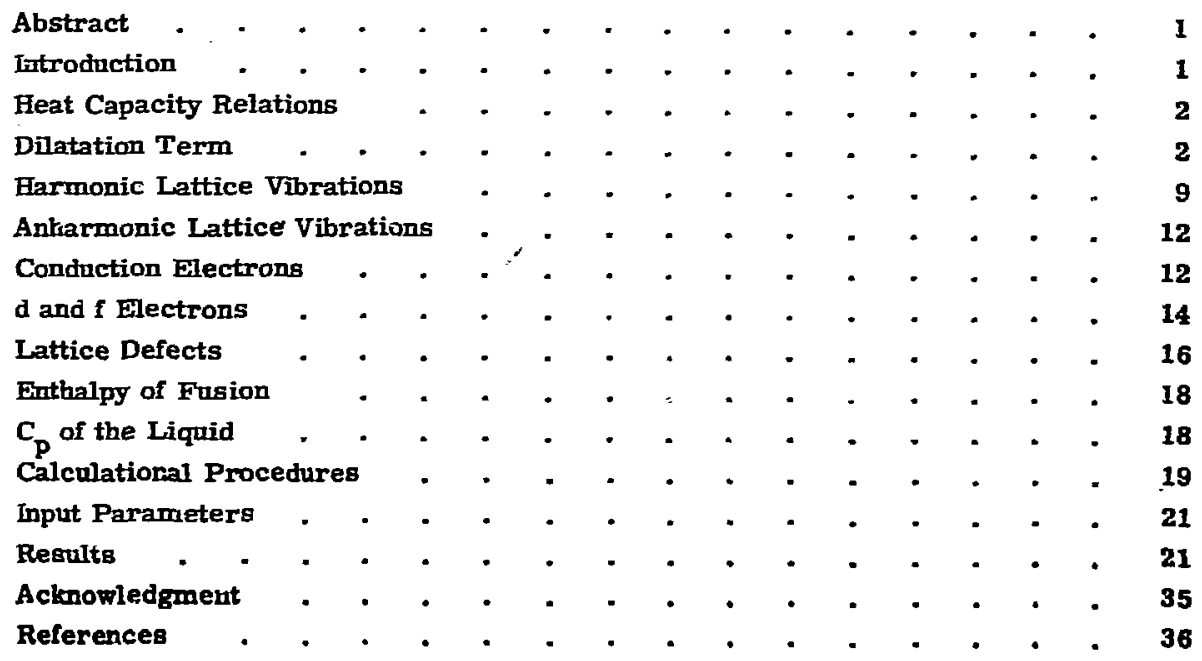




\title{
ESTIMATION OF HEAT CAPACITIES AND OTHER THERMODYNAMIC PROPERTIES OF REFRACTORY BORIDES
}

\begin{abstract}
High-temperature heat capacities and other related thermodynamic functions of the refractory borides were calculated and the results tabulated.

Theoretical expressions describe the contributions of various factors to the heat capacities $\left(C_{p}\right)$ of crybtalline solids. To apply these expressions to borides, however, a mumber of parameters need to be determined, so correlation methods are developed here for estimating many of these parameters. The correlations are based upon known propertieg of borides, carbides, nitrides, metals, and other compounds. Heat capacity factors that are taken into account are the dilatation term, harmonic and aniarmonic lattice vibrations, the separate contributions of conduction electrons and $d$ or $f$ electrons, and contributions of lattice defects.

An important parameter in the dilatation factor is the thermal expansivity. It is found that thermal expansivity correlates with atomization energy $\left(\Delta \mathrm{F}_{2}\right)$ and degree of tonic or covalent bonding in the componind, Thermal expansivity also varies with temperature as $\mathrm{T}^{0.4}$. If the

Knoop microhardness (b) is used as an approximate measure of the degree of covalent bonding, the thermal expansivity of borides can then be expressed as

$$
\alpha=10 \mathrm{~h}^{-1 / 2} \Delta \mathrm{E}_{\mathrm{a}}^{-1} \mathrm{~T}^{0.4} \text {. }
$$

where $\alpha$ is the volume thermal expansivity in ${ }^{\circ} \mathrm{K}^{-1}, \mathrm{~h}$ is in $\mathrm{kg} / \mathrm{mm}^{2}$ for 50-100 g loads, $\Delta E_{a}$ is in kcal/g-atom, and $T$ is in ${ }^{\circ} \mathrm{K}$.

Other parameters that have been derived by correlation methods are the Grïneisen constant, empirical Debye temperatures for metal and nonmetal constituents, the anharmonic constant $\mathbf{A}$, the heat cspacity coefficient of conduction electrons, energy levels of $f$ electrong in Iantbanides and actinides, and energies and entropies of formation of defects.

Results of the heat capacity and entropy calculations are compared with the accurate data available for borides. Calculated room temperature entropies are meertain by about $\pm 10 \%$, but the calculated values of heat capacities at room temperature and above lie within the experimental uncertainties.
\end{abstract}

\section{Introduction}

A fair amount of information bas accumulated in the literature on the basic properties of borides. Crybtalline phases have been identified and structures determined for a mube: of binary boron systems. 1 Phase diagrams are known for 
many of the systems, 2,3 and a variety of thermophysical properties have been measured, 4 in opite of these advances, thermodynamic information on the borides is yet very fragmentary. A basic requirement for thermodynamic calculations is information on heat capacities. Although heat capacity data on borides are very limited, significant advances have been made during the past few years in developing methods for estimating the heat capacities of refractory materials. These methods were reviewed and used, together with innovations developed here. to estimate heat capacities and other thermodynamic properties for the borides.

\section{Heat Capacity Relations}

The heat capacity at constant pressure, $C_{p}$ is the quantity thet is ordinarily needed for calculations of thermadynamic equilibrie, $C_{p}$ is related to $C_{q}$ the heat capacity at constant volume, by the wellknown thermodyamic relation

$$
c_{p}=C_{v}+\frac{a^{2} \bar{V} T}{p} .
$$

where $\alpha$ is the volume thermal expansivity, $\frac{1}{\bar{V}}\left(\frac{\partial V}{\partial x}\right)_{P^{\prime}} \bar{\nabla}$ is the molar volume, and $\beta$ is the isothermal compresslbility, $-\frac{1}{V}\left(\frac{B V}{B P}\right)_{T}$. The quantity, $\alpha^{2} \mathrm{~V} T / \beta$, is known as the dilatation term. $C_{v}$ is made up of contribntions from geveral factors that can be aummerized as followr: $c_{v}=c_{l}+c_{a}+c_{e}+c_{b}+c_{d}$.

where $C_{l}$ is the contribution of barmonic lattice vibrations and constitutes the main factor, $C_{a}$ is a term that accounta for anbarmonic lattice vibrations, $\mathrm{C}_{\mathrm{e}}$ is the heat capacity of the conduction electrons, $C_{8}$ is the heat capacity of electronic contributlons of d or I electrons, and $C_{d}$ is the hent cxpacity of lattice defects auch as vacancies. These various heat capacity factore either are not known or cannot adequately be derived from experimental dats or theoretical sreatments for most of the materiala of interest. To evaluate them, empi-ical or correlation methods must be used, at least in part.

\section{Dilatation Term}

Following the approach uged by Hoffman and co-vorkers, 5 the dilatation term may be rewritten in ferms of the Grineisen coustant as

$$
\frac{\alpha^{2} \overline{\mathrm{V}} \mathbf{T}}{\boldsymbol{B}}=\alpha \boldsymbol{\gamma}_{\mathrm{G}} \mathbf{T C _ { \ell }} .
$$

where $\boldsymbol{T} \boldsymbol{G}$, the Gruinelsen constant, is equal to $\propto \overline{\mathrm{V}} / \mathrm{BC} \mathrm{C}_{\boldsymbol{l}}$. Evaluation of the dilatation terin therefore wili depend upon the evaluation of $\alpha$ and $\boldsymbol{T}_{\mathbf{G}^{*}}$. The dilata- tion term sontributes less than $1 \%$ to the heat capacity of borides at room temperature, but increases to a contribution of about $15 \%$ at the joride melting point.

The estimation of thermal expansivity will be considered first. There are at present no satisfactory methods for making quantitative calculations; but useful correlations can be made, based on such factors as heat capacity, melting point, or band energies. These correlations . 
are most successful if they are restricted to isotropic or nearly isotropic structares and to specific classes of substances.

Before thermal expansivities can be compared, an expression is needed to describe the temperature variation of thermal expansivity. For the special case of metals, it is convenient to use a corresponding states form based upon melting point. Assuming a powerdeprendence of volnme with temperature gives

$$
\frac{v-\nabla_{0}}{\nabla_{m}-V_{0}}=\left(\frac{T}{T_{m}}\right)^{n} \text {. }
$$

where 0 and in refer to temperatures of $0^{\circ} \mathrm{K}$ and the melting point, and $\mathrm{n}$ is a parameter to be determined from experimental data. In terms of thermal expansivity, the expression becomes

$$
\frac{a}{a_{m}}=\frac{V_{m}}{V}\left(\frac{T}{T_{m}}\right)^{n-1},
$$

where $\alpha_{m}$ represents the thermal expansivity at the melting point, and is given by

$$
\alpha_{m}=\frac{n\left(V_{m}-V_{0}\right)}{T_{m} V_{m}} .
$$

Examination of the avallable data (e.g.s see Ref. 6) on metals with the common bcc, hcp, and fcc structures shows that with $n \approx 1.4$, and $\left(v_{m}-v_{0}\right) / v_{m} \approx 0.08$, an adequate description is obtained of the behavior of these metals from room tem- perature to the melting point. ${ }^{*}$ Hence, for these metals, $\alpha_{\mathrm{m}} \approx 0.11 \mathrm{~T}_{\mathrm{m}}^{-1}$; and since $\mathrm{V}_{\mathrm{m}} / \mathrm{V}$ is about 1 , or somewhat larger than 1 , then

$$
\alpha=0.12 \mathrm{~T}_{\mathrm{m}}^{-1.4} \mathrm{~T}^{0.4} \text {. }
$$

Similarly, for refractory compounds, 6 $n$ is found to be -1.4 , but $\alpha_{\mathrm{m}}$ does not correlate well with $T_{n^{*}}$. A better correlation for refractory compounds is obtained between $\alpha$ and $\Delta \mathrm{E}_{2}$, the atomization energy per gram atom. This is illustrated in Fig. 1 by plotting $\propto T^{-0.4}$ vs $\Delta \mathrm{E}_{\mathrm{a}}^{-1}$ for a number of borides, carbides, and nitrides. The sources of data are summarized in Table 1, where thermal expangivities are belfeved to be accurate to within $\pm 5 \%$ for the borides and carbides, and within $\pm 10-20 \%$ for the nitrides. For the metal-rich compositions sush as MB, $\mathrm{MB}_{2}, \mathrm{M}_{2} \mathrm{C}, \mathrm{MC}$, and $\mathrm{MN}$, the data may be described by

$$
\alpha=\mathrm{C} \Delta \mathrm{E}_{\mathrm{a}}^{-1} \mathrm{~T}^{0.4}
$$

where $C$, the slope of the $\alpha \mathbf{r}^{-0.4}$ vB $\Delta \mathrm{F}_{\mathrm{a}}^{-1}$ curve, is about $0.24 \mathrm{cal} / \mathrm{g}$-atom- ${ }^{-} \mathrm{K}^{\mathrm{i}} \cdot 4$.

It is appareat from Fig. 1 that a considerable number of compounds lie both above and below the curve of slope 0.24.

\footnotetext{
* Thermal expansivity is generally given in tife itterature as the mean linear expansivity from room temperature to some bigher temperature, Linear expansivity may be readily converted to rolume expansivity by multiplying by 3 . The mean expansivity over the femperature interval, a(T-298), may be converted to an instantaneous expansivity, $\alpha$ at temperature $T$. by use of Eg. (4); thus,

$$
\begin{aligned}
\alpha & =\frac{v_{298}}{V_{T}} \cdot \frac{n(1-298 / T)}{1-(298 / T)^{n}} \cdot a_{(T-298)} \\
& \approx \frac{1.4(1-298 / T)}{1-(298 / T)^{1.4}} \cdot{ }^{G}(T-298)
\end{aligned}
$$
}




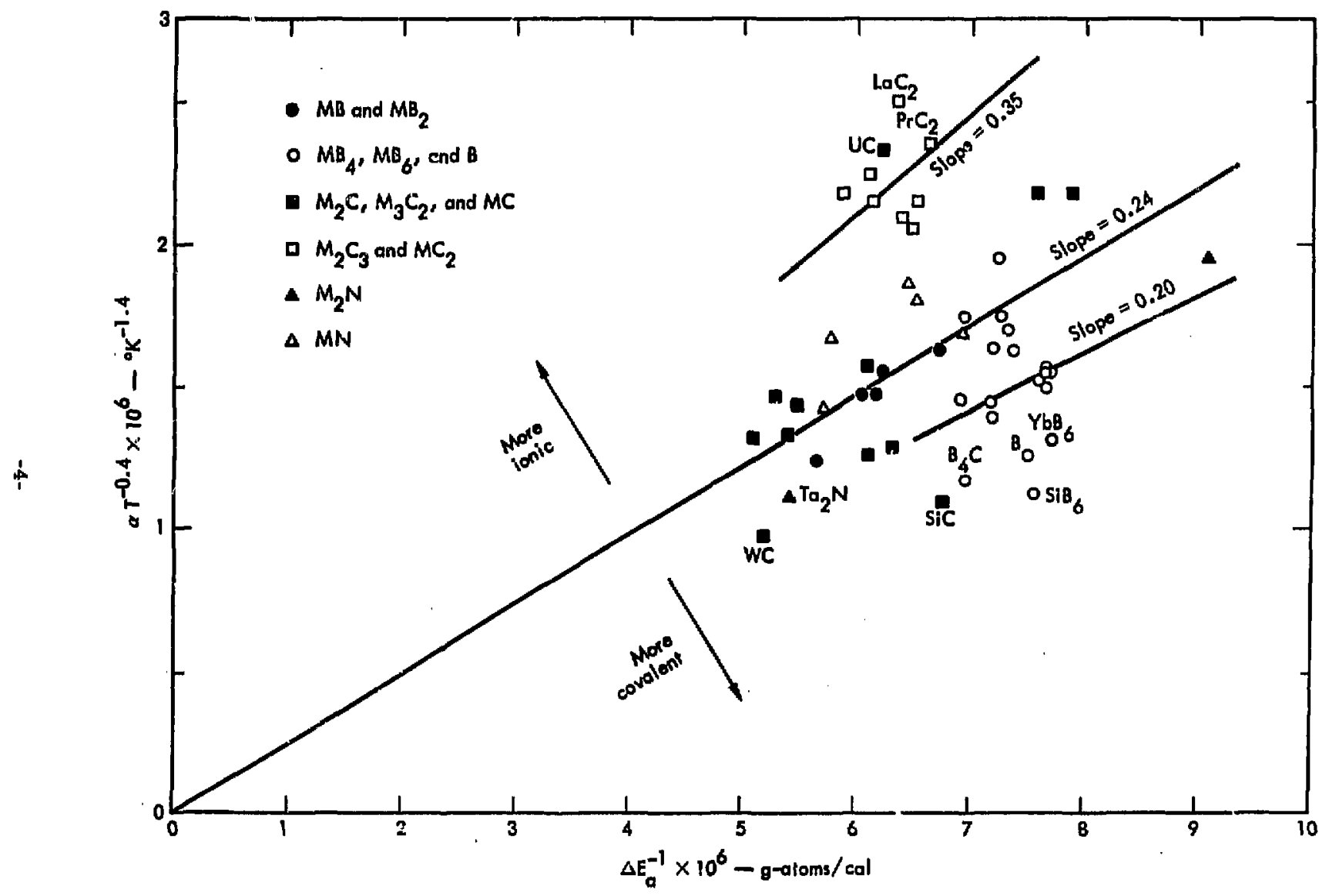

Fig. 1. Dependence of thermal expansivity on atomization energy for borides, carbides, and nitridee. 
Table 1. A summary of atomization energy and thermal expansivity data for borides, carbides, and nitrides. ${ }^{a}$

\begin{tabular}{|c|c|c|c|c|}
\hline Substance & $\begin{array}{l}-\Delta \mathrm{H}_{\mathrm{f}, 298}^{\circ} \\
\mathrm{kcal} / \mathrm{mole}\end{array}$ & $\begin{array}{c}\Delta \mathrm{H}_{\text {sub,298 }}^{\mathrm{o}}(\mathrm{M}) \mathrm{a}^{\mathrm{b}} \\
\text { kcal/mole } \\
\end{array}$ & $\begin{array}{c}\Delta E_{a} \\
\text { kcal/g-atom } \\
\end{array}$ & $\begin{array}{c}a_{T} T^{-0.4}{ }^{c} \\
{ }^{\circ} K^{-1.4} \\
\times 10^{-6} \\
\end{array}$ \\
\hline WB & $\sim 17^{d}$ & 203.4 & 177 & 1.24 \\
\hline $\mathrm{TiB}_{2}$ & $66.8 \quad(8)$ & 112.3 & 148 & $1.62 \quad(6)$ \\
\hline $\mathrm{ZrB}_{2}$ & $73.0 \quad(8)$ & 145.5 & $16 \check{2}$ & $1.47 \quad(6)$ \\
\hline $\mathrm{HfB}_{2}$ & 80.0 (8) & 148.0 & 165 & $1.47 \quad(6)$ \\
\hline $\mathrm{NbB}_{2}$ & 41.9 (8) & 172.4 & 160 & $1.55 \quad(6)$ \\
\hline $\mathrm{B}_{4} \mathrm{C}$ & $14.0 \quad$ (9) & - & 144 & 1.17 (6) \\
\hline $\mathrm{ThB}_{z}$ & $5 z^{e}(10)$ & $137 .:-$ & 144 & $1.45 \quad(6)$ \\
\hline $\mathrm{CaB}_{6}$ & $-72 \quad(11)$ & -42.6 & 130 & $1.49(12)$ \\
\hline $\mathrm{SrB}_{6}$ & $\sim 72 \quad$ (11) & 39.3 & 130 & $1.54(12)$ \\
\hline $\mathrm{BaB}_{6}$ & $\sim 72 \quad$ (11) & 43.9 & 131 & $1.56(12)$ \\
\hline $\mathrm{YB}_{6}$ & $-72 \quad(11)$ & 101.5 & 139 & $1.39(12)$ \\
\hline $\operatorname{LaB}_{6}$ & $-72 \quad(11)$ & 103.0 & 139 & $1.44(12)$ \\
\hline$C \in B_{6}$ & $-72 \quad$ (11) & 101 & 139 & $1.63(12)$ \\
\hline $\mathrm{PrB}_{6}$ & $-72 \quad(11)$ & 85.0 & 236 & $1.69(12)$ \\
\hline $\mathrm{NdB}_{6}$ & $\sim 72$ & 78.3 & 136 & $1.62(12)$ \\
\hline $\mathrm{SmB}_{6}$ & $-72 \quad(11)$ & 49.4 & 131 & $1.52(12)$ \\
\hline $\mathrm{EaB}_{6}$ & $\sim 72 \quad$ & 41.9 & 130 & $1.54(12)$ \\
\hline $\mathrm{GdB}_{6}$ & $-72 \quad(11)$ & 95.0 & 138 & $1.95(12)$ \\
\hline $\mathrm{TbB}_{6}$ & $\sim 72 \quad(11)$ & 92.9 & 138 & $1.74(12)$ \\
\hline $\mathrm{YbB}_{6}$ & $\sim 72$ & 36.3 & 130 & $1.31(12)$ \\
\hline $\mathrm{ThB}_{6}$ & $54.5^{\mathrm{e}}(10)$ & 137.5 & 144 & $1.74(12)$ \\
\hline $\operatorname{SiB}_{6}$ & $-20^{f}$ & 107.7 & 132 & $1.12(6)$ \\
\hline$B(\beta-r h d)$ & - & - & 133 & $1.25(18)$ \\
\hline $\mathrm{MO}_{2} \mathrm{C}$ & $5.5(13)$ & 157.3 & 164 & $1.26 \quad(6)$ \\
\hline $\mathrm{Cr}_{3} \mathrm{C}_{2}$ & $5.5(13)$ & 95.0 & 127 & 2.18 \\
\hline SiC & 16.5 (8) & 107.7 & 148 & 1.09 \\
\hline TiC & $44.1(13)$ & 112.3 & 164 & 1.57 \\
\hline $\mathrm{ZrC}$ & $47.0(13)$ & 145.5 & 182 & 1.43 \\
\hline EfC & $50.1(13)$ & 148.0 & 185 & $1.33 \cdot(6)$ \\
\hline$v C_{0.88}$ & $24.5(13)$ & 122.9 & 159 & 1.29 \\
\hline $\mathrm{NbC}$ & $33.6(13)$ & 172.4 & 189 & 1.46 \\
\hline $\mathrm{TaC}$ & $34.1(13)$ & 186.9 & 196 & 1.32 \\
\hline WC & $9.7(13)$ & 203.4 & 192 & 0.97 \\
\hline UC & $23.3(13)$ & 126.3 & 160 & 2.32 \\
\hline $\mathrm{PuC}_{0.9}$ & 12 (13) & 84.1 & 132 & 2.18 (6) \\
\hline
\end{tabular}


Table 1 (continued).

\begin{tabular}{|c|c|c|c|c|}
\hline Substance & $\begin{array}{l}-\Delta \mathrm{H}_{\mathrm{L}, 298}^{\circ} \\
\mathrm{kcal} / \text { mole }\end{array}$ & $\begin{array}{c}\Delta H_{\text {sub, } 298}^{\sigma}(\mathrm{M}), \mathrm{b} \\
\text { kcal/mole }\end{array}$ & $\begin{array}{l}\Delta E_{\mathrm{a}}, \\
\mathrm{kcal} / \mathrm{g} \text {-atom }\end{array}$ & $\begin{array}{l}\alpha_{\mathrm{T}} \mathrm{T}^{-0.4}{ }^{\mathrm{c}} \\
{ }^{\circ} \mathrm{K}^{-1.4} \\
\times 10^{-6} \\
\end{array}$ \\
\hline $\mathrm{La}_{2} \mathrm{C}_{3}$ & $\sim 50 \mathrm{~B}$ & 103.0 & 154 & 2.05 \\
\hline $\mathrm{Ce}_{2} \mathrm{C}_{3}$ & $-50^{\mathrm{g}}$ & 101 & 153 & 2.15 \\
\hline$\tilde{U}_{2} C_{3}$ & $51 \quad(13)$ & 126.3 & 164 & 2.25 \\
\hline $\mathrm{LaC}_{2}$ & $\sim 25^{\mathrm{g}}$ & 103.0 & 157 & 2.50 \\
\hline $\mathrm{CeC}_{2}$ & $\sim 258$ & 101 & 156 & 2.09 (4) \\
\hline $\operatorname{PrC}_{2}$ & $\sim 25^{B}$ & $\approx 5.0$ & 151 & $2.35 \quad(4)$ \\
\hline ThC $_{2}$ & $29.7(13)$ & 137.5 & 170 & $2.18 \quad(6)$ \\
\hline $\mathrm{UC}_{1.9}$ & $20.0(15)$ & 126.3 & 163 & $2.15(i 4)$ \\
\hline $\operatorname{Ta}_{2} N$ & 64.7 (9) & 186.9 & 184 & 1.11 (4) \\
\hline $\mathrm{Cr}_{2} \mathrm{~N}$ & $27.3 \quad$ (9) & 95.0 & 110 & 1.95 (4) \\
\hline TIN & $80.4 \quad(9)$ & 112.3 & 153 & 1.79 (i) \\
\hline$\overline{2} \mathbf{r N}$ & $87.3 \quad$ (9) & 145.5 & 173 & $1.65(6)$ \\
\hline BfN & $88.2 \quad(9)$ & 148.0 & 175 & 1.42 (4) \\
\hline $\mathrm{TN}$ & $51.9 \quad(\theta)$ & 122.9 & 144 & 1.68 (4) \\
\hline UN & $70.4(9)$ & 126.3 & 155 & $1.85(15)$ \\
\hline
\end{tabular}

a The numbers in parentheses are Reference numbers.

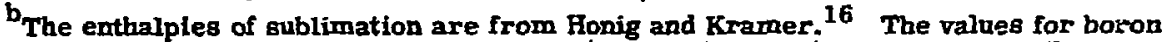
and carbon are 133.0 (Ref. 8) and $171.3 \mathrm{kcal} / \mathrm{g}$-atom (Ref. 16) respectively. The enthalpy of formation of atomic nitrogen is $113.0 \mathrm{kcal} / \mathrm{g}$-atom.

$c_{T h e} \alpha_{T} T^{-0.4}$ values are derived $\mathrm{fx}$ im thermal expansivity data extending from room temperature to somewhere in the range of $800-1500^{\circ} \mathrm{C}$.

- $\mathrm{d}_{\mathrm{Brewer}}$ and Faralden estimate $\Delta \mathrm{H}_{\mathrm{f}, 298}^{0}$ of WB to be between -22 and $-12 \mathrm{kcal} / \mathrm{mole}^{17}$

$\mathrm{e}_{\text {The }} \Delta \mathrm{F}_{\mathrm{f}}^{\circ} 298$ of $\mathrm{ThB}_{4}$ and $\mathrm{ThB}_{6}$ are assumed to be equal to their free energies of formation at $850^{\circ} \mathrm{C}$. 10

$f_{\text {The }} \Delta \mathrm{H}_{\mathrm{f}, 298}^{\mathrm{n}}$ of $\mathrm{SiB}_{6}$ is assumed to be about the same as that of $\mathrm{B}_{4} \mathrm{C}$ and SiC.

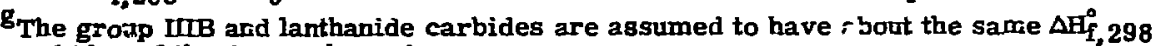
as carbides of thorium and urarium.

Compounds with the highest and lowegt expansivities are identified with fornulas in Fig. 1 and show that the highest expansivities correspond to carbides of the group IIIB, lanthanide, and actinide elements, whereas the lowest expansivities are repiresented by compounds that have a high degree of covalent bonding. The group IIIB, lanthanide, and actinide carbldes show a number of properties that are characteristic of ionic bonding. For example, the ease of hydrolysis of these carbides to form acetylene and other hydrocarbons attests to their galt-like character. Similar vaicies of thermal expansivity are anticipated for $\mathrm{CaC}_{\text {, }}$ and other group IIA carbides. For these salilike carbides, $C \approx 0.35 / \mathrm{g}-$ atom- $^{\circ} \mathrm{K}^{1.4}$, or

$$
a=0.35 \Delta \mathrm{E}_{\mathrm{a}}^{-1} \mathrm{~T}^{0.4} \text {. }
$$


For the highly covalent compounds such as the tetraborides and hexaborides, $\mathrm{C} \approx 0.20 \mathrm{cal} / \mathrm{g}$-atom- ${ }^{\circ} \mathrm{K}^{1.4}$, and

$$
\alpha=0.20 \Delta \mathrm{E}_{\mathrm{a}}^{-1} \mathrm{~T}^{0.4} \text {. }
$$

Although borides such as hexaborides or dodecaíorides are expected to have a. large ionic contribution to the bonding between metal and the boron network, ${ }^{12}$ the structural framework that primarily determines the thermal expansivity is provided by covalent B- $\mathbf{S}$ bonds.

It would appear that if a guantitative ineasure of the degree of ionic or covalent bonding in the bonds that determine thermal expansivity can be found, then a more quantitative expression can be given for thermai expansivity. A property that shows promise for such a correlation is microhardness, Knoop microhardness values $^{4,13}$ range from $\sim 600 \mathrm{~kg} / \mathrm{mm}^{2}$ near the top of Fig. 1 to $-4000 \mathrm{~kg} / \mathrm{mm}^{2}$ near the bottom. Empirically, the thermal expansivity may be related to microhardness by,

$$
\alpha=10 \mathrm{~h}^{-1 / 2} \Delta \mathrm{E}_{\mathrm{a}}^{-1} \mathrm{~T}^{0.4}
$$

where $h$ is the Knoop microhardness in $\mathrm{kg} / \mathrm{mm}^{2}$ for loads of $50-100 \mathrm{~g}$. This relationship is illustrated in Fig. 2 for the compounds from Table 1 for wich microhardness data are available.

In order Łn evaluate $\boldsymbol{\gamma}_{G}$, a tabulation is made of tine available room temperature data on borides, carbides, nitrides, and several typical oxides (see Table 2). Thermal expansivities have been extrapolated to room temperature, when necessary, by assuming that $\alpha$ is proportional to $\mathrm{T}^{0.4}$. When several values of compressibility were given for a single compound in the references to Table 2 , the values were averaged. The heat capacity values are actually $C_{p}$ values, but the error is negligible in assuming them to be equal to $C_{\ell}$ at room temperature. Similarly, no distinction is made between isothermal and adiabatic compressibilities. The uncertainties in $\bar{V}$ and $C_{l}$ are believed to be negligible, and the uncertainties in $\alpha$ and $\beta$ are believed to be about $\pm 10 \%$ each. Hence, ${ }^{\gamma_{G}}$ is uncertain by about $\pm 15 \%$.

Examination of the $\boldsymbol{\gamma}_{G}$ data shows that a definitie trend exisus in $\boldsymbol{\gamma}_{\mathrm{G}}$ with class of substance. It seems reasovable to assign a $\gamma_{G}$ value of 1.2 for the borides and carbides, and 1.4 for the nitrides and oxides. These values may be compared with an average $\boldsymbol{\gamma}_{G}$ value of 1.84 for the common metals - Na, K, Al, Mn, Fe, $\mathrm{Co}, \mathrm{Ni}, \mathrm{Cu}, \mathrm{Ag}$, and $\mathrm{Pt}$ - while the rare earths (with the exception of $\mathrm{Eu}$ ) have values in the range of 0.3 to 1.2 .27

The temperature dependence of $\boldsymbol{\gamma}_{\mathbf{G}}$ has been determined for $T i B_{2}, Z_{20}$, and Hf $_{2}$ by Wiley and co-workers, ${ }^{20}$ who found $\boldsymbol{\gamma}_{\mathbf{G}}$ values that are nearly constant from room temperature to $1300^{\circ} \mathrm{K}$. Manning and Hunter ${ }^{28}$ found values in the range of 1.0-1.2 for $\gamma_{G}$ of $\mathrm{Y}_{2} \mathrm{O}_{3}, \mathrm{Ho}_{2} \mathrm{O}_{3}, \mathrm{Er}_{2} \mathrm{O}_{3}$ : $\mathrm{Tm}_{2} \mathrm{O}_{3}$, and $\mathrm{Lu}_{2} \mathrm{O}_{3}$ from room temperatore to $1300^{\circ} \mathrm{K}$. The values either remained constant or decreased by a few percent over the temperature interval. Similarly, Soga and Anderson ${ }^{29}$ found $\gamma_{G}$ to be approximately constant at 1.3 for $\mathrm{Al}_{2} \mathrm{O}_{3}$ from 300-1400 K, and 1.5 for $\mathrm{MgO}$ from $300-1100^{\circ} \mathrm{K}$. From the thermal data on tungsten, ${ }^{8,21} \gamma_{G}$ values are calculated to increase uniformly from 1.5 at $300^{\circ} \mathrm{K}$ to 1.8 at $1500^{\circ} \mathrm{K}$. Kleppa ${ }^{30}$ found that, for most low-melting-point metals, $\gamma_{G}$ shows no appreciable change in going 


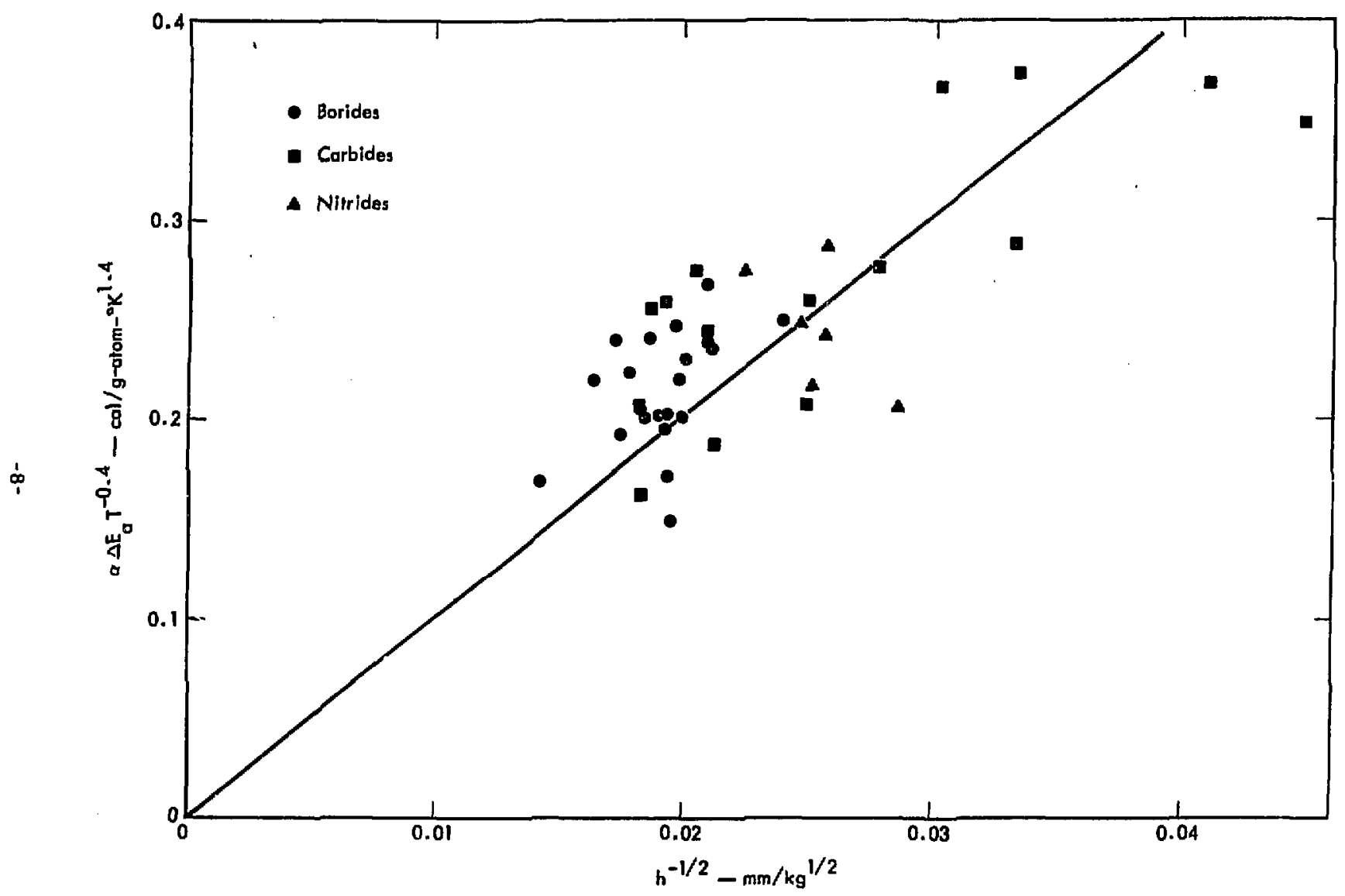

Fig. 2. Dependence of the product $\alpha \Delta \mathrm{F}_{\mathrm{a}} \mathrm{T}^{-0.4}$ on microhardnese (h). 
Table 2. Room temperature values of thermal expansivity, molar volume, compressibulity, heat capacity, and Grüneisen gamma for a number of refractory avbstances. $a$

\begin{tabular}{|c|c|c|c|c|c|}
\hline Substance & $\begin{array}{l}a,{ }^{0} \mathrm{~K}^{-1} \\
\times 10^{-5} \\
\end{array}$ & $\overline{\mathrm{v}}, \mathrm{cm}^{3} /$ mole & $\begin{array}{c}\text { B. } \mathrm{cm}^{2} / \text { dyne } \\
\times 10^{-12} \\
\end{array}$ & $\begin{array}{c}C_{\ell} \\
\text { ergs/mole-ox } \\
\times 10^{8} \\
\end{array}$ & ${ }^{\boldsymbol{\gamma}_{\mathbf{G}}}$ \\
\hline$B(\beta-r h d)$ & $1.3(18)$ & $4.60 \quad(1)$ & $0.56(19)$ & $1.11(25)$ & 1.0 \\
\hline C(diam) & $0.4 \quad(6)$ & $3.42(19)$ & 0.19 (19) & $0.61(25)$ & 1.2 \\
\hline $\mathrm{TiB}_{2}$ & $1.6 \quad(6)$ & $15.38 \quad(4)$ & $0.47(20)$ & $4.39 \quad(8)$ & 1.2 \\
\hline $\mathrm{ZrB}_{2}$ & 1.4 (6) & 18.53 (4) & $0.46(20)$ & $\begin{array}{l}4.82 \quad(8) \\
\end{array}$ & 1.2 \\
\hline $\mathrm{HfB}_{2}$ & 1.4 (6) & 17.87 (4) & $0.49(20)$ & $5.02 \quad(8)$ & 1.0 \\
\hline $\mathrm{B}_{4} \mathrm{C}$ & 1.1 (6) & $21.94 \quad(4)$ & $0.39(21)$ & $5.26(25)$ & 1.2 \\
\hline TiC & $1.6 \quad(6)$ & 12.18 (4) & 0.48 (4) & $3.36(25)$ & 1.2 \\
\hline ZrC & 1.4 (6) & $15.50 \quad(4)$ & $0.47(21)$ & $3.79(25)$ & 1.2 \\
\hline UC & 2.3 (6) & 18.35 (4) & $0.61(22)$ & $5.01(13)$ & 1.4 \\
\hline TiN & 1.8 (6) & 11.38 (4) & $0.34 \quad(4)$ & $3.71(25)$ & 1.6 \\
\hline UN & 2,1 (6) & 17.60 (4) & $0.54(23)$ & $4.78(26)$ & 1.4 \\
\hline BeO & $1.8 \quad(6)$ & $8.32(19)$ & $0.46(24)$ & $2.54(25)$ & 1.3 \\
\hline $\mathrm{MgO}$ & 2.9 (6) & $11.25(19)$ & $0.62(19)$ & $3.78(25)$ & 1.4 \\
\hline $\mathrm{Al}_{2} \mathrm{O}_{3}$ & 1.7 (6) & 25.57 (19) & $0.38(19)$ & 7.80 (25) & 1.4 \\
\hline $\mathrm{ThO}_{2}$ & $2.0(6)$ & 26.38 (19) & $0.56(21)$ & $6.10(25)$ & 1.5 \\
\hline $\mathrm{DO}_{2}$ & $2.3 \quad(6)$ & $24.62(19)$ & $0.62(21)$ & $6.41(25)$ & 1.4 \\
\hline
\end{tabular}

The numbers in parentheses are Reference numbers.

from the solid at room temperature to the liquid at moderately elevated temperatures. As exceptions, Kleppa noted that bismuth and gallium undergo a decrease in $\boldsymbol{\gamma}_{\mathbf{G}}$ from about 2.2 to 1.1 upon melting, which is an effect that can be attributed to a gtructural change associated with the melting of these metals. From these observations it is concluded that $\boldsymbol{\gamma}_{\boldsymbol{G}}$ is nearly independent of temperature for crystalline substances, provided that drastic changes in structure do not occur. Caution should be exercised in extending this conclusion below romm temperature, where $\boldsymbol{\gamma}_{\mathbf{G}}$ could charge considerably and, in exceptional cases, as with Si and InSb, 31 may actually become negative.

\section{Harmonic Lattice Vibrations}

The heat capacity contribution of harmonic lattice vibrations, $C_{p}$, will be examined next. Hoffman et al. 5 found that Debye functions were suitable for describing the low-temperature heat capacities of binery compounds of metals with nonmetals, provided that two Debye temperatures were assigued to each 
compound: one for the metal and the other for the nonmetal constituent. Pairs of Debye temperatures were thus selected for a series of compounds to give a best fit to the low-temperature heat capacity data (see Table 3). Hoffman et al. further showed that if all atoms in a crystal have equal mean-square displacements, then the metal and nonmetal Debye temperatures will be inversely proportional to the square roots of the corresponding masses; i.e., $\theta_{R} / \theta_{X}=\left(M_{X} / M_{R}\right)^{1 / 2}$. For eleven compounds consisting of carbides, nitrides, oxides, and fluorides (see Table 3 ), the ratio $\theta_{\mathrm{R}} / \theta_{\mathrm{X}}$ was found to agree within a fartor of two with $\left(M_{X} / M_{R}\right)^{1 / 2}$ (see Ref. 5). Kaufman ${ }^{32}$ calculated $\boldsymbol{\theta}_{R}$ and $\theta_{\mathbf{X}}$ values for diborides of $\mathrm{Ti}, \mathrm{Zr}$, $\mathrm{HF}, \mathrm{Nb}$, and Ta (gee Table 3) by using Hoffman's relation, $\theta_{R} / \theta_{X}=\left(M_{X} / M_{R}\right)^{1 / 2}$, tozether with the condition that $S_{298}^{\circ}$ values calculated by Debye functions (with suitable dilatation and electronic terms added) must be in agreement with the experimental $S_{298}^{\circ}$ values. Kaufman presents a comparison between the heat capacities calculated on the basis of $\boldsymbol{\theta}_{\mathbf{R}}$ and $\boldsymbol{\theta}_{\mathbf{X}}$ values and experimental data. Agreement between calculation and experiment is generally poor at $50^{\circ} \mathrm{K}$ or lower: but, with the exception of $\mathrm{HFB}_{2}$, agreement is within $7 \%$ at $100^{\circ} \mathrm{K}$ and improves to within $2 \%$ at $350^{\circ} \mathrm{K}$. For $\mathrm{HrB}_{2}$, the comparison ahows large discrepancies throughout the temperature range and indicates failure of the equal mean-square displacement assumption in this case.

Schick calculated $\theta_{R}$ and $\theta_{X}$ for refractory borides by means of a modified form of the Lindemann relation, i.e., $\theta_{\mathrm{i}}^{\prime}=\mathrm{KT}_{\mathrm{c}}^{1 / 2} \mathrm{M}_{\mathrm{i}}^{-1 / 2} \mathrm{v}_{\mathrm{i}}^{-1 / 3}$. Here, $\theta_{\mathrm{i}}^{\prime}$ represents $\theta_{R}$ (or $\theta_{X}$ ), $K$ is the Lindemam coistant (which is taken to be 137), $T_{c}$ is the melting point of the compound, and $M_{i}$ and $V_{i}$ represent the atomic weight and atomic volume of pure element $R$ (or X). A comparison of Schick's results with those of Kaufman (see Table 3) shows that Schick's $\theta_{\mathfrak{R}}$ values are lower and his $\theta_{X}$ values higher than Kaufman's. Schick's calculated $S_{298}^{\circ}$ and $C_{p, 298}$ values are in general agreement with experimental data for the diborides listed in Table 3; but, for the diborides of chromium and molybdenum, Schick's $S_{298}^{0}$ values are about $2 \mathrm{cal} / \mathrm{mole}-^{\circ} \mathrm{K}$ higher than the experimental data.

Examination of the data in Table 3 suggests yet a simpler method for estimating $\theta_{\mathbf{R}}$ and $\boldsymbol{\theta}_{\mathbf{X}} \cdot \theta_{\mathbf{R}}$ seems to shom little change with type of refractory compound, as, for example, a $\theta_{\mathbf{R}}$ of about $251-320^{\circ} \mathrm{K}$ for $\mathrm{HiB}_{2}$ may be compared with $275^{\circ} \mathrm{K}$ for $\mathrm{HfO}_{2}$. Furthermore, a $\boldsymbol{\theta}_{\mathrm{R}}$ appears to sorrelate well with $\theta_{R^{\prime}}^{\circ}$ the Debje temperature for the pure elemental metal. The ratio $\theta_{R} / \theta_{R}^{0}$ is found to have a mean value of 1.38 and an uncertainty of about t0.3 (see Table 3). For borides, a value of 1.7 for $\theta_{R} / \theta_{R}^{\circ}$ provides a better fit to the data. The nonmetal contributions, $\theta_{X}$, also appear to be reasonably constant for a given class of compound. For borides, a $\theta_{X}$ of approximately $1210^{\circ} \mathrm{K}$ is consistent with a $\theta_{R} / \theta_{R}^{\circ}$ value of 1.7 . There is an obvious decrease in $\theta_{\mathrm{X}}$ and an increase in ionic bonding, in going from borides to carbides, nitrides, oxides, and fluorides.

The method developed here will be used for the heat capacity calculations. It has an advantage over Hoffman's method in that it does not require low-temperature calorimetric data for input. The estimated 
Table 3. Debye temperatures of the metal $\left(\theta_{R}\right)$ and nonmetal $\left(\theta_{X}\right)$ constituents of various compounds, and a comparison of $\theta_{\mathrm{R}}$ with $\theta_{\mathrm{R}}^{\circ}$, the Debye temperature of the elemental metal.

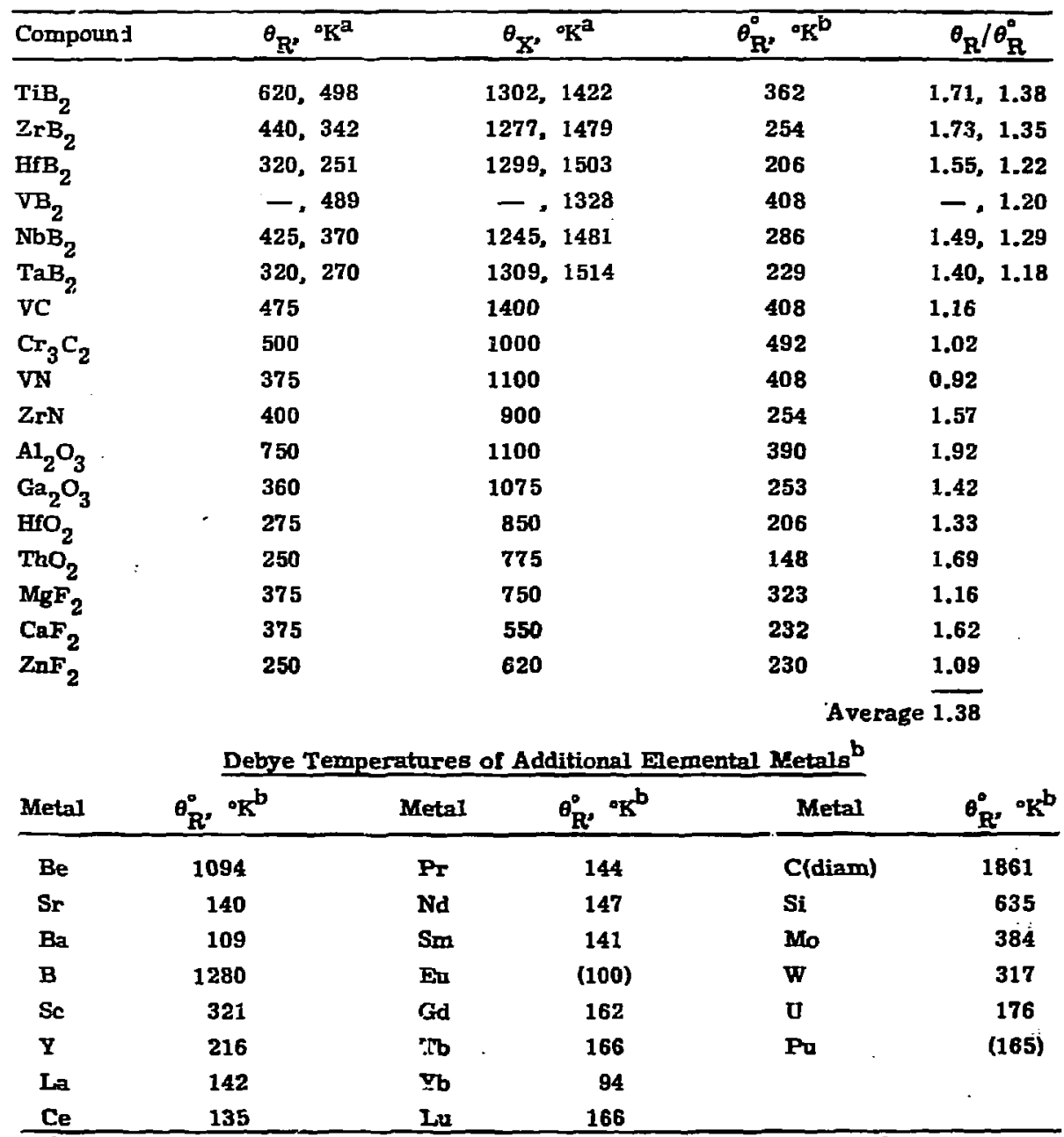

${ }^{a_{T}}$ The first entries of $\theta_{\mathrm{R}}$ and $\theta_{\mathrm{X}}$ for the diborides are from Raufman, ${ }^{32}$ and the second entries are from Schick. ${ }^{8}$ The single entries of $\theta_{R}$ and $\theta_{X}$ for the remaining compounds are from Hoffman et al. 5

$b_{\text {The }} \theta_{\mathrm{R}}^{\circ}$ values for the lanthanide metals are from Ggchneidner. 27 When data were given on both sound velocity and heat capacity results, 27 the values were averaged.

$\theta_{R}^{\circ}$ for Eu and $P u$ were estimated. For the remaining metals, $\theta_{R}^{\circ}$ was calculated from the low-temperature heat capacity data given by Hultgren et al 33 Suitable corrections were applied for electronic heat capacity contributions in making these calculations. $\theta_{\mathrm{R}}^{\circ}$ for boron, carbon, and salcon were derived from heat capacity data at $150-400^{\circ} \mathrm{K}$. For $\mathrm{Sr}$ and $\mathrm{Ba}$, the temperature range used was 7-20 $\mathrm{K}$; for the other metals, $50-100^{\circ} \mathrm{K}$ was Ired. 
${ }^{\theta}{ }_{R}$ and ${ }^{\theta} X$ values may not give re!iable heat capacity estimates at low temperatures, but should give reasonable values for $S_{298}^{\circ}$ and for $C_{l}$ at room temperature and above.

\section{Anharmonic Lattice Vibrations}

The contributions to the heat capacity from anharmonic lattice vibrations have the theoretical form

$$
C_{a}=A C_{\ell} T \text {, }
$$

where $A$ is a parametric constant that depends in a complex manner on the harmonic and anharmonic coefficients of the potential energy curve. ${ }^{34}$ The functional dependence of thermal expansivity on the parmonic and anhnemonic coelficients is generally simllar to that of $A,{ }^{34}$ and a correlation should exist between $a$ and $A$.

Experimentel determinations of $A$ are limited to those of Overton, ${ }^{35}$ who made meagurements on sodium and copper. He found that $A$ for sodinm from $0-200^{\circ} \mathrm{K}$ is $6 \times 10^{-5} \cdot \mathrm{K}^{-1}$, but, from $200-300^{\circ} \mathrm{K}$, $\mathrm{A}$ increases very rapidiy. A likely explanation of this rapid increase is that it originates from vacancy contributions to the heat capaciby. The lower temperature value is therefore taken to be the correct ane. In the case of copper, Overton concluded that the anharmonic contributions to the beat capacty are approcimately zero at room temperature. His data ghow considerable scatter, with anharmonic contributions ranging from $0-1 \%$ of the total heat capacty from $70-300^{\circ} \mathrm{K}$. It is conceivable that the anharmonic contribution may be as much as $0.5 \%$ at $300^{\circ} \mathrm{K}$, which would give an $A$ value of 1.7 $\times 10^{-5}{ }^{-1} \mathrm{~K}^{-1}$.

From the expectation that $A$ values should correlate with thermal expansivity. they should also correlate with $\Delta \mathrm{E}_{\mathrm{a}}^{-1}$. Using the sodium $A$ value and taking $25,755 \mathrm{cal} / \mathrm{g}$-atom for $\Delta \mathrm{F}_{\mathrm{a}}$ (Ref. 16) gives

$$
A=1.5 \Delta \mathrm{E}_{\mathrm{a}}^{-1}
$$

as a possible correlation expression. Similarly, using the estimated A value for copper and $80,500 \mathrm{cal} / \mathrm{g}$-atom for $\Delta \mathrm{F}_{\mathrm{a}}$ (Ref. 16) gives $A=1.4 \Delta \mathrm{E}_{\mathrm{a}}^{-1}$, which is better agreement than could be expected. Considering the general lack of data on the ankarmonic factor, Eq. (13) will be assimed to apply to the borides or, indeed, to substances in general. Fortunately, the anharmonic contribution to the heat capactty is sufficiently amall that little error is introduced into the $C_{p}$ calculations from the large uncertainties in this term.

\section{Conduction Electrons}

The contribution of conduction electrons to the heat capactio is represented by

$$
c_{e}=\boldsymbol{T}_{e} \mathbf{T}, \text { (Refs. 5,34) }
$$

Where $\gamma_{e}$ is the heat capacity ceefficient of the conduction electrons. It may be shown theoretically that $\boldsymbol{r}_{\mathrm{e}}$ depends on the concentration of conduction electrons 
and on the density of energy states of the conduction electrons at the Fermi energy level. ${ }^{34}$ The theory is not adequate to permit quantitative calculations of $\boldsymbol{Y}_{\epsilon}, 80$ experimental means are needed for its determination. It is determined most easily from low-temperature $C_{p}$ data. Below $\sim 20^{\circ} \mathrm{K}, \mathrm{C}_{\mathrm{e}}$ is a major contributor to the heat capacity of metallic materials, and $C_{p}$ is given by

$$
C_{p}=\gamma_{e} T+B T^{3}
$$

where $\mathrm{BT}^{3}$ is the Debye contribution. $A$ plot of $C_{p} / T$ vB $T^{2}$ may be used to determine $\gamma_{e}$ as the $0^{\circ} \mathrm{K}$ intercept. ${ }^{34}$

The avallable values of $\boldsymbol{\gamma}_{\mathrm{e}}$ for borides are eummarized is Table 4, where a mumber of $\gamma_{e}$ values for metals $\left(\gamma_{e,},{ }\right)$ have been incladed for comparison. The boride $\gamma_{e}$ palues generals $y$ tend to correlate with $\gamma_{e, ~}$, but several inconsistently high values also occur. Perhaps this should not be surprising since the functional dependence of the density of energy states with Fermi energy (or with electronto-atom ratio) is irregular across a raw of the periodic table (e.g., see Ret. 43), and may show several sharp peaks.

The temperature depandence of $\tau_{e}$ is nsually assumed to be emall; but, if the Fermi energy is at or near a peak in the density of energy states, then $\tau_{e}$ will bave a large temperature dependence. Theoretical calculations by Ostenburg and co-worbers ${ }^{43}$ on the temperaturedependence of $\boldsymbol{\gamma}_{e}$ for nlobium and molybdemum, and for allogs of $\mathrm{Nb}-\mathrm{MO}, \mathrm{Nb}-\mathrm{TC}_{\mathrm{C}}$ and Mo-TC, show that high values of $\gamma{ }^{\circ}$ as is found for Nb, whl decreage markedly with temperature; and low values, as in Mo, will ohow a slight increase. At high temperatures, the $\gamma_{e}$ values of these metals approach roughly a common value. It thus appears that unusually high values of $\boldsymbol{\gamma}_{\mathrm{e}}$ derived from low-temperature data ghould not he used at high temperatures. An estimate of the high-temperature $\boldsymbol{T}_{e, M}$ may be made from comparisons with zeighboring elements.

Examination of the data in Table 4 shows that, for the diborides, $\gamma_{e} \approx 0.3 \gamma_{e}, M^{*}$ With lower boran contents, $\boldsymbol{T}_{\mathrm{e}}$ should approach the metal value, For $\mathrm{MB}_{6}$ and $\mathrm{MB}_{12}$, Matthisg ${ }^{37}$ has ouggested that $\boldsymbol{T}_{\mathrm{e}}$ should be representative of the value for pure boron wth a cubic atructure. The data of Table 4, however, would suggest that the metal atoms bave an influence in determining $\boldsymbol{\gamma}_{e}$. A Iactor that may be algnifficant for these higher borides is the valence of the metal atom. For example. yttarblum, which to belleved to be partly in the +2 state in a number of tis compounds, ${ }^{27}$ has a relatively low $\tau_{e}$ in the heoraboride as compared to the pare metal

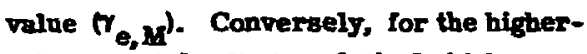
valeace metals, $\gamma_{e}$ is relatively high, as in $\mathrm{ThB}_{6}$ and $\mathrm{ZrB}_{12}$. On the basis of these various qualitative observations, predictions for $\boldsymbol{\gamma}_{\mathrm{e}}$ of the various borides are summarized as follows:

\begin{tabular}{|c|c|}
\hline Boride & $T_{e}$, cal $/$ mole- ${ }^{-1} \mathrm{~K}^{2}$ \\
\hline $\mathbf{M B}_{\boldsymbol{z}}$ where $\mathrm{n} \leq 2$ & $\left(\frac{1}{n+1}\right)^{\tau_{e, 1}}$ \\
\hline$M(+2) B_{4}, 6,12$ & $0.4 \gamma_{\mathrm{e}, \mathrm{m}}$ \\
\hline $\mathrm{M}(+3) \mathrm{B}_{4,6,12}$ & $0.8 \gamma_{\mathrm{e}, \mathrm{M}}$ \\
\hline $\mathbf{M}(+4,+5,+6) \mathbf{B}_{4,6,12}$ & $1.2 \gamma_{e, M}$ \\
\hline
\end{tabular}

The uncertaiuties in these estimgtes for $\gamma_{e}$ at high temperatures are belfeved to be $\$ 50 \%$. 
Table 4. Comparisons of the electronic gamma for borides with those for elemental metals. ${ }^{a}$

\begin{tabular}{|c|c|c|c|c|c|c|}
\hline Boride & 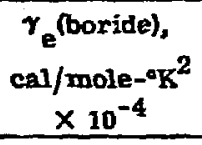 & $\begin{array}{c}\gamma_{a, M^{(m e t a l)}{ }^{33}} \\
\text { cal/g-atom- }{ }^{2} \mathrm{~K}^{2} \\
\times 10^{-4} \\
\end{array}$ & Boride & $\begin{array}{r}\gamma_{\mathrm{e}^{\text {(boridel }}} \\
\text { cal/mole-0 } \\
\times 10^{-4} \\
\end{array}$ & & 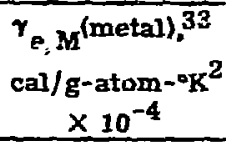 \\
\hline $\mathbf{M n}_{2} B$ & $16.4 \quad(36)$ & 30 & $\mathrm{MnB}_{2}$ & 6.7 & (36) & 30 \\
\hline $\operatorname{MnB}$ & 13.1 (36) & 50 & $\mathrm{UB}_{2}$ & 22.5 & (38) & 24.6 \\
\hline $\mathrm{TiB}_{2}$ & $2.3^{b}(32)$ & 8.25 & $\mathrm{YB}_{6}$ & 6.8 & (37) & 20 \\
\hline $\mathrm{ZrB}_{2}$ & $1.7^{b}(39)$ & 7.0 & $\mathrm{LaB}_{6}$ & $24.9,15.3^{\mathrm{C}}$ & (40) & 27.5 \\
\hline $\mathbf{H F B}_{2}$ & $1.8^{b}(41)$ & 5.8 & $\mathbf{Y b B}_{6}$ & 2.4 & (40) & 6.93 \\
\hline & $5.8^{b}(42)$ & $18.75^{d}$ & $\mathrm{ThB}_{6}$ & 11.5 & (40) & 12.2 \\
\hline $\mathrm{TaB}_{2,1}$ & $4.7^{b}$ (32) & $13.5^{\mathrm{d}}$ & $\mathrm{ZrB}_{12}$ & 13.5 & (37) & 7.0 \\
\hline
\end{tabular}

Electronic Gamma for Additional Elemental Metals 33

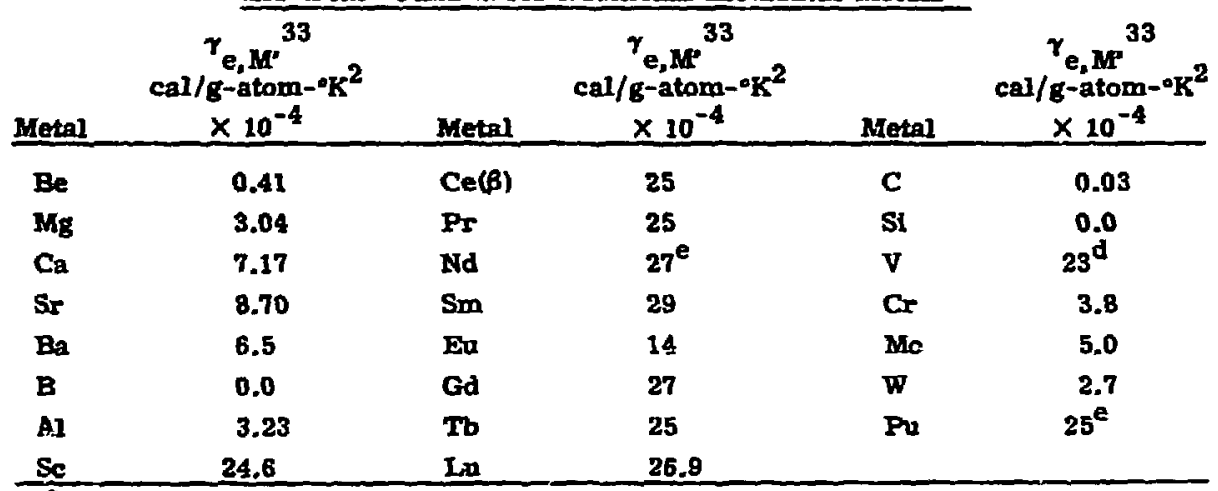

Tine numbers in parentheses are Reference numbers.

$b_{\text {The }} \gamma_{e}$ values were calculated from the low-temperature $c_{p}$ cata.

CThe first value corresponds to a sample prepared by the reduction of $\mathrm{La}_{2} \mathrm{O}_{3}$ with a mixture of boron and carbon, while the second corresponds to a sample prepared by reduction with boron alone.

${ }_{Y_{E}, M}$ for $V, N b$, and $T a$ at bigh temperatures are eatimated to be $10 \times 10^{-4}, 9 \times 10^{-4}$, and $8 \times 10^{-4} \mathrm{cal} / \mathrm{g}$-atom- $0 \mathrm{~K}$, respectively.

$\boldsymbol{e}_{\boldsymbol{e}, \mathrm{M}} \mathbf{M}$ values for $\mathrm{Nd}$ and $\mathrm{Pa}$ were estimated.

\section{d and f Electrons}

The electronic heat capacity of $d$ or $f$ electrons, $C_{B}$ arises either from spinorder magnetic transitions 19,44 or from Schottky anomalies corresponding to the thermal excitation of electronic energy states. 45 These eflects are generally found in elements or compounds of the $3 d$ transition series, the lanthanides, and 
actinides. The crostal field interaction with $d$ electrons is very strong in the $3 d$ series, so it becomes difficult to distinguish d electron contributions from other heat capacity effects. Magmetic transitions may be readily identified for this series when experimental data are available, but otherwise are difficult to predict. For the lanthanides and actinides and their compounds, the $4 f$ and $5 f$ electrons are well screened so that the crystal field interaction is weak. Consequently, these substances have energy states at levelg comparable to those in the free atom or ion. Since lanthanides and actinides typically have a large number of low-lying levels, the Schottly contribution to the heat capacity will be large. Magnetic spin-order transitions are also common in the lanthanide and actinide serles.

Magmetic ordering transitions characteristically shoi a lambda-shaped heat capacity curve that is a consequence of cooperative order-disorder transformations. The crdered state is ferromagnetic, antiferromagnetic, or ferrimagnetic, and the disordered atate, paramagnetic. For lanthanides and actinides and their compounds, magnetic transitions generally occur well below room temperature and involve a relatively small number of energy levels. 44,46-48 Because of the smallness of the effect, it is adequate for our purposes to treat the heat capacity of these substances in the same mamer as for Schotthy anouwalies. For elements and compounds of the 3d transition series. however, magnetic th ansitions may occur above or below room temperature and may make a significant contribution to the heat capacity. Because of the uncertainties inyolved in predicting the existence and magnitude of magnetic transitions in the 3d series, predictions will not be made.

For Schottky anomalieg, the heat capacity is calculated from the expres$\operatorname{sion}^{45,47}$

$$
\begin{aligned}
C_{s}= & \frac{1}{R T^{2}}\left\{\frac{\sum_{i} E_{i}^{2} g_{i} \exp \left(-E_{i} / R T\right)}{\sum_{i} g_{i} \exp \left(-E_{i} / R T\right)}\right. \\
& \left.-\left[\frac{\sum_{i} E_{i} g_{i} \exp \left(-E_{i} / R T\right)}{\sum_{i} g_{i} \exp \left(-E_{i} / R T\right)}\right]\right\}
\end{aligned}
$$

provided that the energy levels are known. Dennison and Gechneidner 45 calculated the Schottky heat capacity contributions of a number of trivalent lanthanide lons and of divalent samarium. Contributions to $C_{s}$ above room temperature were found to be of the order of 2 cal $/ \mathrm{g}$-atom-a $\mathrm{K}$. Below room temperatare, $C_{8}$ was negligible except for $\mathrm{Sm}^{+2}$ and $\mathrm{Er}^{+3}$.

A serious drawback of Demison and Gschneidner's calculations is that they did not take into account the effects of crystal field on the energy levels. This is particulariy important for the ground state, where degenerate energy levels within a few hundred $\mathrm{cm}^{-1}$ of the lowest energy state contribute significantly to $C_{s}$ at room temperature and belor. An empirical treatment of low-temperature heat capacity data by Westrum and coworkers on $\mathrm{NaB}_{6}$ (Ref. 47) indicates that the ten-fold degenerate ${ }^{4} I_{9 / 2}$ Eround state is split into two levels at $0 \mathrm{~cm}^{-1}$, four levels at $80 \mathrm{~cm}^{-1}$, and four levels at $224 \mathrm{~cm}^{-1}$. Similar studies on $\mathrm{GdB}_{6}$ 
(Ref. 48) indicate, for the ${ }^{8} \mathrm{~S}_{7 / 2}$ ground state, two 1evels at $0 \mathrm{~cm}^{-1}$, four at $51 \mathrm{~cm}^{-1}$. and two at $80 \mathrm{~cm}^{-1}$. The heat capacity curves for $\mathrm{NdB}_{6}$ and $\mathrm{GdB}_{6}$ show thermal anomalies extending over most of the 0-298 $\mathrm{K}$ range. Unpublished work on $\mathrm{CeB}_{6}$ (Rer. 46) shows similar behavior. A schottky anomaly for $\mathrm{UB}_{2}$ (Ref. 38) may be interpreted to correspond to one level at $0 \mathrm{~cm}^{-1}$ and two levels at $122 \mathrm{~cm}^{-1}$. Other levels are too far remaved to contribute to the heat capacity up to $350^{\circ} \mathrm{K}$. Data on lembda and Schottly anomalies have been presented by Westrum and coworkers ${ }^{44,46}$ for several other lanthanide and actinide compounds.

From the inalted information avallable, It may be surmised that the crystal fleld oplitting is generally greater for the actinides than for the lantbanides. The following scheme is therefore chosen for estimeting the crystal field splitting of the groknd state for the borides. For the lanthanide borides, two levels are assigned to $0 \mathrm{~cm}^{-1}$, four levels to $60 \mathrm{~cm}^{-1}$, and the balance of the multiplicity is pleced at $180 \mathrm{~cm}^{-1}$. For the actiride borides, one level is assigned to $0 \mathrm{~cm}^{-1}$, two levels to $120 \mathrm{~cm}^{-1}$, and the balance to $360 \mathrm{~cm}^{-1}$. For the lanthanide ions, the multiplicity of the lovels is given by $(2 J+1)$. For the setinide ions, a partial breakdown of spin-orbit coupling occuri. 44 Hence, for calculational purposes, an aperage of $2 J+1$ and $2 S+1$ fill ba used ag a best guess of the multiplicity for actinide lons.

\section{Lattice Defects}

The heat cepacity of lattice defects, $C_{d}$ depends upon the concentration of defects and upon their energies of formatlon. For a defect concentration in thermodyngmic equiltbrium with the lattice,

$N_{d}=\exp \left(\Delta S_{d} / R\right) \exp \left(-\Delta E_{d} / R T\right)$.

Where $N_{d}$ is the ratlo of defects to lettice aiteg, and $\Delta S_{d}$ and $\Delta D_{d}$ are the entropy and energy of defect formation, respectively. Aaguming $\Delta S_{\mathrm{d}}$ and $\Delta E_{\mathrm{d}}$ to be lndependent of temperature and volume, the hest capacity of defects is obtained by differentiating $\mathbf{N}_{d} \cdot \Delta E_{d}$ with regpect to $T$, resulting in

$$
\begin{aligned}
C_{d}=\left(\Delta E_{d}^{2} / B T^{2}\right) & \exp \left(\Delta S_{d} / R\right) \\
& x \exp \left(-\Delta F_{d} / R T\right) .
\end{aligned}
$$

Equation (18) is similar in form to the Schottigy heat capacty for a single excited
Btate given by Eq. (16), and consequemtly it is not possible to distinguish between the heat capacity of a Schottly anomaly and of a lattice defect on the basis of heat capacity data alone.

In the case of elemental metals, experimental studies of diffusion, thermal expansion, and quenching as well as heat capacity have establighsd the primary importance of schottky racancies in the lattice. $34,48,50$ Vacancy concentrations are found to be of the order of $1 \%$ of the lattice aites near the melting point. Heat capacity measurements provide the most reliable values of the energies and entropies of vacancy formation, while methods based on theremal expansion or quenching tend to give vacancy concentrations that are too $10 \mathrm{w}$. 50 Diffusion data are useful for setting an upper bound to the energy 
of racancy formation, since the activation energy for diffesion is the sam of the formation and migration energies. Typically, $\Delta \mathrm{E}_{\mathrm{d}}$ for vacancy formation is 0.5-0.6 of the activation energy for diffusion. 34,48
Eramination of heat capacity data on racancies in metals ${ }^{50}$ shows that correlations may be made of both $\Delta E_{d}$ and $\Delta S_{d}$ with the atomization energy (Ref. 16), $\Delta E_{a}$ (see Fig. 3). These correlations are summarized by the equations

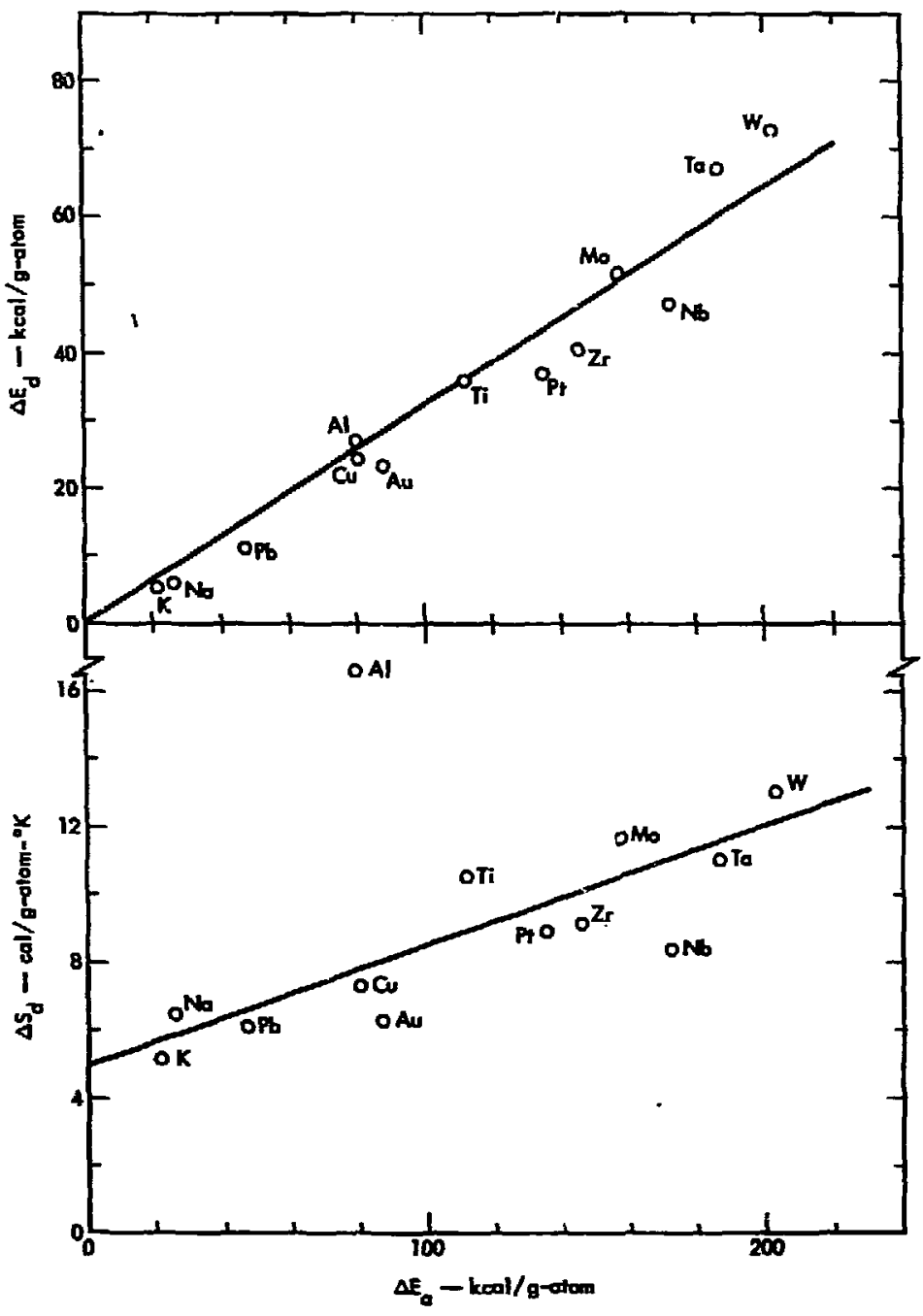

Fig. 3. Correlation of the energy and entropy of vacancy formation for metals with the energy of atomization. 


$$
\Delta \mathrm{E}_{\mathrm{d}}=0.32 \Delta \mathrm{E}_{\mathrm{a}}
$$

and

$\Delta S_{d}=5.0+3.5 \times 10^{-5} \Delta E_{a}$.

Substitution of Egs. (19) and (20) in (17) or (18) allows the calculation of the concentration ano beat capacity of vacancies for metals.

For compounds, a variety of defects may result from Schattky or. Frenkel disorder, impurity effects, or lattice vacancies in nonstoichiometric componnds. 34,51 Taking a strictiy empirical approach and ignoring the types of defects, there is evidence that the activation energy for diffusion will still correlate with atomization energy. Based on data given by Swalin for halides and chalcogenides, 52 the relation $\Delta E_{\text {diffusion }}=0.6 \Delta E_{a}$ holds well for cation diffusion and is crudely correct for anion diffusion." If one sssumes that $\Delta E_{\mathrm{d}}=0.55 \Delta E_{\text {diffusion, then }} \Delta E_{\mathrm{d}}=0.33$ $\Delta E_{a}$, which is in substantial agreement with Eq. (19). On the basis of this agreement, it is assurned that Eqs. (19) and (20) are generally applicable te metals and compounds, including borices. Uncertainties in the predicted $\Delta E_{d}$ and $\Delta \mathrm{S}_{\mathrm{d}}$ are probably about $\pm 20 \%$.

\section{Enthalpy of Fusion}

The enthalpy of fusion, $\Delta \mathrm{H}_{\mathrm{m}}^{\circ}$ may be obtained by estimating the entropy of fusion. and applying the relation, $\Delta \mathrm{H}_{\mathrm{m}}^{\circ}=\mathrm{T} \Delta \mathrm{S}_{\mathrm{m}}^{\circ}$. For borides with boiron contents less than in $\mathrm{MB}_{4}, \Delta S_{\mathrm{m}}$ is estimated to be $2.3 \mathrm{cal} / \mathrm{g}-$ atom- ${ }^{\circ} \mathrm{K}$, a value that is comparable to that for close-packed metals. ${ }^{33}$ For borides with boran contents equal to or higher than in $\mathrm{MB}_{4}, \Delta S_{m}^{\circ}$ is taken to be an additive combination with $2.3 \mathrm{cal} / \mathrm{g}-$ atom- ${ }^{\circ} \mathrm{K}$ for the metallic constitue,st, and
$4.0 \mathrm{cal} / \mathrm{g}$-atom- ${ }^{\circ} \mathrm{K}$ for the boron. A high entropy of fusion for the boron part is justified on the bagis of the rigid covalenttype bonding exhibited by borides with high boron contents. Other elements with covalent characteristics in the solid, such as $\mathrm{Si}$, Ge, red $\mathrm{P}$, $\mathrm{Sb}, \mathrm{Bi}$ and $\mathrm{Te}$, have eutropies of fusion in the range of $4-8 \mathrm{cal}$ / g-atom-" K. The estimates above sur the enthalpies of fusion of borides are believed to be uncertain by about $\pm 25 \%$.

\section{$C_{p}$ of the Liquid}

There is no experimentai information at the present time on the heat capacities of liguld refractory materials. Qualitatively, the heat capacity is belleved to behave as follows. At temperatures within a few hundred degrees above the melting point, a complex behavior is expected to occur as remnants of the crystalline struc- ture gratually break down. Within this interval, the heat capacity may decline, it may remain relatively constant, and/or it may show one or more humps. Be-

\footnotetext{
On the basis of more limited information, a similas relationship is found betweep the free energy of diffusion and $\Delta \mathrm{E}_{\mathrm{a}} \cdot \mathrm{S2}^{\mathrm{t}}$
} 
cause of the unknown structural changes upon melting, it is not possible to predict whether $\mathrm{C}_{p}$ for the liquid will be greater or less than for the solid at the melting point. As the temperature increases beyond the first few hundred degrees, $C_{p}$ will rise because of the dilatation term, as well as various contributions from vibrational, electronic, and other excitation processes. For purposes of thermodynamic calculations, $C_{p}$ for the liquid boride will be assumed to be constant from the melting point to $4000^{\circ} \mathrm{K}$, and to have a value eçal to that of the solid at the melting point.

\section{Calculational Procedures}

In addition to $\mathrm{C}_{\mathrm{p}}$, calculations were made of $S_{298,}^{\circ} H_{298}^{\circ}-H_{0}^{\circ}, H_{T}^{\circ}-H_{298}^{\circ}$, and $\left(\mathrm{F}_{T}^{\circ}-\mathrm{H}_{298}^{\circ}\right) / \mathrm{T}$, where $T$ goes from 298 to $4000^{\circ} \mathrm{K}$. $C_{p}$ values were calculated at intervals of $2^{\circ} \mathrm{K}$ up to $300^{\circ} \mathrm{K}$, and at intervals of $5^{\circ} \mathrm{K}$ up to $4000^{\circ} \mathrm{K}$. Other thermodynamic functions were derived from the $C_{p}$ values by using appropriate summations to approximate the required integrals. (Calculations were made on a Control Data Corporation CDC-6600 computer. $)^{*}$

For convenience in making computer calculations, the Debye heat capacity contributions were expressed in the form

$$
C_{\ell}=\frac{d E_{\ell}}{d T}=\frac{d}{d T}\left[9 R T\left(\frac{T}{\theta}\right)^{3} \mathrm{D}\left(\frac{\theta}{T}\right)\right],
$$

where

$$
D\left(\frac{\theta}{T}\right)=\int_{0}^{\theta / T} \frac{x^{3} d x}{e^{x}-1} .
$$

Equation (21) may be approximated by

$$
\frac{d E_{\ell}}{d T} \approx \frac{\Delta E_{\ell}}{\Delta r}=\frac{9 R}{2 \theta^{3} \Delta T}
$$

\footnotetext{
Reference to a company or product name does not imply approval or recommendation of the product by the University of California or the U. S. Atomic Energy Commission to the exclusion of others that may be suitable.
}

$$
\begin{aligned}
x & {\left[(T+\Delta T)^{4} D\left(\frac{\theta}{T+\Delta T}\right)\right.} \\
& \left.-(T-\Delta T)^{4} D\left(\frac{\theta}{T}\right)\right],
\end{aligned}
$$

where $\Delta \mathbf{T}$ represents a sufficiently small temperature increment that errors in $\mathrm{C}_{2}$ become negligibly small. The temperature increments of $2^{\circ} \mathrm{K}$ below room temperature and $5^{\circ} \mathrm{K}$ above room temperature adequately meet this requirement, as they introduce less than $0.01 \%$ error into $C_{l}$ or the other thermodynamic functions at temperatures of $298^{\circ} \mathrm{K}$ and higher. The Debye function, $D(\theta / T)$, may be svaluated by writing it in the form

$$
D\left(\frac{\theta}{T}\right)=\int_{0}^{\infty} \frac{x^{3} d x}{e^{x}-1}-\int_{\theta / T}^{\infty} \frac{x^{3} d x}{e^{x}-1} .
$$

The first integral is equal to $\tau^{4} / 15$, and the second integral is solved by the series method given by Stegun. 53

The cornplete heat capacity equation for binary compounds may now be written as follows:

$$
\begin{aligned}
C_{p}= & \left(1+\operatorname{c\Delta E}_{a}^{-1} \gamma_{G} T^{1.4}\right. \\
& \left.+1.5 \Delta E_{a}^{-1} T\right)\left({ }_{N} C_{l, R}\right.
\end{aligned}
$$




$$
\begin{aligned}
& \left.+\mathrm{N}_{\mathrm{X}} \mathrm{C}_{\mathrm{l}, \mathrm{X}}\right)+\gamma_{\mathrm{e}} \mathrm{T}+\mathrm{N}_{\mathrm{R}} \mathrm{C}_{\mathrm{S}, \mathrm{R}} \\
& +\frac{\Delta \mathrm{E}_{\mathrm{d}}^{2}}{\mathrm{RT}^{2}} \exp \left(\frac{\Delta \mathrm{S}_{\mathrm{d}}}{\mathrm{R}}-\frac{\Delta \mathrm{E}_{\mathrm{d}}}{\mathrm{RT}}\right) .
\end{aligned}
$$

where $C$, the thermal expansion parameter, may be determined from Egs. (8)-(11); $\boldsymbol{\gamma}_{G}$ is the Grineisen constant; $\Delta \mathrm{E}_{\mathrm{a}}$ is the atomization energy per gram atom for the compound; $\mathrm{N}_{R}$ and $\mathrm{N}_{X}$ are the atom fractions of metal $R$ or nonmetal $X$ in the compound; $C_{\ell, R}$ and $C_{\ell, X}$ are the Debye heat capacities as calculated from Eqs. (22) and (23); and, based on $\theta_{\mathrm{R}}$ and $\theta_{\mathrm{X}}$ estimated by methods described in the text, $\gamma_{e}$ is the heat capacity coefficient for conduction electrons and is also estimated by methods given in the text; $C_{5, R}$ is the Schottky heat capacity given by Eq. (16): and $\Delta E_{d}$ and $\Delta S_{d}$ are the energy and entropy of vacancy formation from Eq8. (19) and (20).

The method of summation used to approximate the-integrals for the other thermodynarific functions is illustrated for the case of $\mathrm{H}_{298.15}^{\circ}-\mathrm{H}_{0}^{\circ}$ (which, for brevity, is written as $\left.\mathrm{H}_{298}^{\circ}-\mathrm{H}_{0}^{\circ}\right)$ :

$$
\begin{aligned}
\mathrm{H}_{298}^{\circ}-\mathrm{H}_{0}^{\circ} & =\int_{0}^{298.15} C_{p} \mathrm{dT} \\
& =\sum_{i=0,2}^{i=296} 1 / 2\left(C_{p, i}+C_{p, i+2}\right) \Delta T \\
& +0.15 C_{p, 298^{\circ}} \\
& =1 / 2\left(0+C_{p, 298}\right) \Delta T \\
& +\Delta T \sum_{i=2,2}^{296} C_{p, i}+0.15 C_{p, 298^{\circ}}
\end{aligned}
$$

and, since $\Delta \mathrm{T}=2^{\circ} \mathrm{K}$,

$$
\begin{aligned}
& \mathrm{H}_{298}^{\circ}-\mathrm{H}_{0}^{\circ}=1.15 \mathrm{C}_{\mathrm{p}, 298} \\
&+2 \sum_{\mathrm{i}=2,2}^{296} \mathrm{c}_{\mathrm{p}, \mathrm{i}}
\end{aligned}
$$

The summations used for the remaining functions are

$$
\begin{aligned}
s_{298}^{c}= & \frac{1.15 C_{p, 298}}{297} \\
& +2 \sum_{i=2,2}^{296} \frac{C_{p_{i} i}}{i}+N_{R} \text { Ren } g_{0^{\prime}}
\end{aligned}
$$

$$
\begin{aligned}
\mathrm{H}_{T}^{\circ}-\mathrm{H}_{298}^{\circ} & =4.35 \mathrm{C}_{p, 300} \\
+2.5 C_{p, T}+5 & \sum_{i=305,5}^{T-5} C_{p, i^{\prime}}
\end{aligned}
$$

and

$$
\begin{aligned}
& \frac{F_{T}^{\circ}-H_{298}^{\circ}}{T}= \frac{B_{T}^{\circ}-H_{298}^{\circ}}{T}-S_{298}^{\circ} \\
&-\frac{4.35 C_{p, 300}}{300}-\frac{2.5 C_{p, T}}{T} \\
&+5 \sum_{i=305, i j}^{T-5} \frac{C_{p, i}}{i}
\end{aligned}
$$

where $\Delta T$ has been taken to be $5^{\circ} \mathrm{K}$ above $300^{\circ} \mathrm{K}$, and $\mathrm{E}_{\mathrm{O}}$ is the multiplicity of the lowest energy state. Suitable interpolations are made for nonincremental temperatures. 


\section{Input Parameters}

The input parameters required for the calculations are $\mathrm{C}, \Delta \mathrm{E}_{\mathrm{a}} \cdot \boldsymbol{\gamma}_{\mathrm{G}}, \theta_{\mathrm{P}}, \theta_{\mathrm{X}}$,

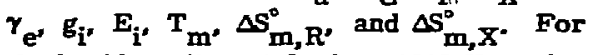
the borides, $\gamma_{G}=1.2, \theta_{X}=1210^{\circ} \mathrm{K}$, and $\Delta S_{m, R}^{2}=2.3 \mathrm{cal} / \mathrm{g}$-atom- ${ }^{\circ} \mathrm{K} ; \theta_{R}$ is taken to be $1.7 \theta_{\mathrm{R}}^{\circ}$, using $\theta_{\mathrm{R}}^{\circ}$ values given in Table 3 ; and $\Delta S_{m, X}^{0}$ is taken to be $2.3 \mathrm{cal} /$ g-atom- ${ }^{\circ} \mathrm{K}$ for boron contents up to $\mathrm{MB}_{4}$ ' and $4.0 \mathrm{cal} / \mathrm{g}$-atom- ${ }^{\circ} \mathrm{K}$ for $\mathrm{MB}_{4}$ and above. $\mathrm{B}_{4} \mathrm{C}$ and the silicon borides are exceptions to this procedure, where $\Delta S_{m}^{\circ}$ for the entire compound is taken to $4.0 \mathrm{cal} / \mathrm{g}$ atom- ${ }^{\circ} \mathrm{K}$. Where several values of $T_{m}$ are available, the values are generally araraged. For peritectic melting compounds, the peritectic temperature is given for $\mathbf{T}_{\mathrm{m}}$. The values used for $\mathbf{C}$, $\Delta E_{a}, \gamma_{e}$, and $T_{m}$ are listed in Table 5 , and values for $g_{i}$ and $E_{i}$ for assumed lanthanide and actinide ionic states are given in Table 6. All other metal ions are assumed to be nondegenerate for the borides listed in Table 5 . In compiling the input data, estimates were made whenever data were not available. The methods of estimation either have been described in the text or footnotes, or are based on trends in the periodic table.

\section{Results}

Values of $S_{298}^{\circ}$ and $C_{p}$ at 298, 1000, and $2000^{\circ} \mathrm{K}$, as calculateô by the methods developed here, are compared in Table 7 with experimental data on borides. Only borides that have reasonably accurate data have been listed.

The experimental $C_{p}$ data on borides are still quite uncertain at temperatures in the neighborhood of $2000^{\circ} \mathrm{K}$. For example, $C_{p}$ values reported for $\mathrm{ZrB}_{2}$ at $2000^{\circ} \mathrm{K}$ by different investigators range from 5.8 to $9.0 \mathrm{cal} / \mathrm{g}$-atom- ${ }^{\circ} \mathrm{K}$. Agreement at $\sim 1000^{\circ} \mathrm{K}$ is much better, usually being within $\pm 10 \%$ for different investigators. Values at room temperature are based on lowtemperature calorimetric methods, and $C_{p}$ values are believed to be accurate to $\pm 2 \%$. Considering the experimental uncertainties, the calculated values provide as good a fit as can be expected for $\mathrm{C}_{\mathrm{p}}$. Unfortunately, the assumptions made here about condaction electron and vacancy contributions at high temperatures cannot be tested because of the uncertainties in the experimental data.

Comparisons of calculated and experimental $S_{298}^{\circ}$ values present a more critical test of the assumptions made in the selection of Debye temperatures. Agreement between calculated and experimental values is found to be generally within $\pm 10 \%$, which is rurprisingly good, considering the empirical nature of the methods used to make the eatimates.

Thermodynamic functions have been calculated for most of the known borides and are gummarized in Tables 8, 9, and 10. The borides of dyoprosium through thulium should be similar in properties to borides of terbium, and hence have not been listed. Borides of iron- and platimum-group metals, and of a mumer of actinides, also are excluded. It shonld be possible to make estimates for these borides by observing trends in the periodic table. 
Table 5. Input paranseters for heat capacity calculations. ${ }^{a}$

\begin{tabular}{|c|c|c|c|c|c|c|}
\hline Boride & 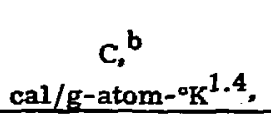 & $\begin{array}{l}-\Delta H_{\mathrm{f}, 298^{\prime}}^{\circ} \\
\mathrm{kcal} / \mathrm{mole}\end{array}$ & $\begin{array}{c}\Delta \mathrm{E}_{\mathrm{a}} \\
\mathrm{kcal} / \mathrm{g} \text {-atom }\end{array}$ & $\begin{array}{c}\gamma_{\mathrm{e}} \\
\mathrm{cal} / \mathrm{mole}^{-\mathrm{ok}^{2}} \\
\times 10^{-4} \\
\end{array}$ & $\begin{array}{c}\mathbf{T}_{\mathbf{m}} \\
{ }^{\circ} \mathrm{K} \\
\end{array}$ & \\
\hline $\mathrm{Be}_{4} \mathrm{~B}$ & $(0.24)$ & (8) & 90 & $(0.33)$ & 1430 & (2) \\
\hline $\mathrm{Be}_{2} \mathrm{~B}$ & $(0.24)$ & (8) & 99 & $(0.27)$ & 1790 & (2) \\
\hline $\mathrm{BeB}_{2}$ & $(0.24)$ & (15) & 120 & $(0.14)$ & (2250) & . \\
\hline $\mathrm{BeB}_{6}$ & $(0.20)$ & (40) & 131 & $(0.16)$ & 2340 & (2) \\
\hline $\mathrm{BeB}_{12}$ & $(0.20)$ & $(60)$ & 133 & $(0.16)$ & $(2000)$ & \\
\hline $\mathrm{MgB}_{2}$ & $(0.24)$ & $22.0 \quad(17)$ & 108 & $(1.0)$ & $(1300)$ & \\
\hline $\mathrm{MgB}_{4}$ & $(0.20)$ & $25.1(17)$ & 118 & (1.2) & (1400). & \\
\hline $\mathrm{MgB}_{6}$ & $(0.20)$ & (30) & 123 & $(1.2)$ & 1420 & (2) \\
\hline $\mathrm{CaB}_{6}$ & $0.194^{d}$ & $-72^{d}$ & 130 & (2.9) & 2510 & (2) \\
\hline $\mathrm{SrB}_{6}$ & $0.200^{\mathrm{d}}$ & $-72^{d}$ & 130 & (3.5) & 2510 & (2) \\
\hline $\mathrm{BaB}_{6}$ & $0.204^{\mathrm{d}}$ & $-72^{d}$ & 131 & (2.6) & 2540 & (2) \\
\hline $\mathbf{A l B}_{2}$ & $(0.24)$ & (15) & 120 & (1.1) & 1250 & (2) \\
\hline $\mathrm{AlB}_{12}$ & $0.164^{e}$ & (80) & 135 & (2.6) & 2450 & (2) \\
\hline $\mathrm{ScB}_{2}$ & $0.237^{\mathrm{e}}$ & (30) & 129 & $(8,2)$ & 2520 & (2) \\
\hline $\mathrm{ScB}_{4}$ & $0.147^{\mathrm{e}}$ & (50) & 134 & $(19.7)$ & $(3000)$ & \\
\hline $\mathrm{ScB}_{12}$ & $(0.20)$ & $(120)$ & 139 & $(19.7)$ & $(2500)$ & \\
\hline $\mathrm{YB}_{2}$ & $(0.24)$ & (30) & 132 & $(6.7)$ & 2370 & (2) \\
\hline $\mathbf{Y B}_{4}$ & $-(0.20)$ & (50) & 137 & $(16.0)$ & 3070 & (2) \\
\hline$Y B_{6}$ & $0.193^{d}$ & $-72^{d}$ & 139 & (16.0) & 2870 & (2) \\
\hline $\mathrm{YB}_{12}$ & $(0.20)$ & (120) & 140 & $(16.0)$ & 2470 & (2) \\
\hline $\mathrm{YB}_{70}$ & $(0.20)$ & (130) & 134 & $(16.0)$ & 2270 & (2) \\
\hline $\mathrm{LaB}_{4}$ & $(0.20)$ & (50) & 137 & $(22.0)$ & 2070 & (2) \\
\hline $\operatorname{LaB}_{6}$ & $0.200^{\mathrm{d}}$ & $-72^{d}$ & 139 & (22.0) & $\mathbf{2 8 0 0}$ & (2) \\
\hline $\mathrm{CeB}_{4}$ & $(0.20)$ & (50) & 137 & $(30.0)$ & $(2400)$ & \\
\hline $\mathrm{CeB}_{6}$ & $0.226^{d}$ & $\sim 72^{d}$ & 139 & $(30.0)$ & 2510 & (2) \\
\hline $\operatorname{PrB}_{4}$ & $(0.20)$ & (50) & 133 & $(20.0)$ & $(2600)$ & \\
\hline $\operatorname{PrB}_{6}$ & $0.230^{d}$ & $-72^{d}$ & 136 & $(20.0)$ & (2700) & \\
\hline $\mathrm{NdB}_{4}$ & $(0.20)$ & (50) & 132 & (21.6) & $(2800)$ & \\
\hline $\mathrm{NdB}_{6}$ & $0.220^{d}$ & $-72^{d}$ & 136 & $(21.6)$ & 2810 & (2) \\
\hline $\mathrm{SmB}_{4}$ & $(0.20)$ & (50) & 126 & $(11.6)$ & $(2800)$ & \\
\hline $\operatorname{Sin}_{6}$ & $0.200^{8}$ & $-72^{d}$ & 131 & (11.6) & 2740 & (2) \\
\hline $\mathrm{EuB}_{6}$ & $0.201^{d}$ & $-72^{d}$ & 130 & $(5.6)$ & $(2520)$ & \\
\hline $\mathrm{GdB}_{2}$ & $(0.24)$ & (30) & 130 & $(9.0)$ & 2740 & (2) \\
\hline $\mathbf{G d B}_{4}$ & $(0.20)$ & (50) & 135 & $(21.6)$ & $(2800)$ & \\
\hline $\mathrm{GdB}_{6}$ & $0.269^{d}$ & $-72^{d}$ & 138 & (21.6) & $(2800)$ & \\
\hline $\mathbf{G d B}_{100}$ & $(0.20)$ & (130) & 134 & $(21.6)$ & (2270) & \\
\hline $\mathbf{T b B}_{2}$ & $0.239^{d}$ & (30) & 130 & (8.3) & $(2200)$ & \\
\hline
\end{tabular}


Table 5 (continued).

\begin{tabular}{|c|c|c|c|c|c|c|c|c|}
\hline Boride & $\begin{array}{c}c,^{b} \\
\mathrm{cal} / \mathrm{g} \text {-atom-o' } \mathrm{K}^{1.4}\end{array}$ & $\begin{array}{l}-\Delta \mathrm{H}_{\mathrm{f}, 2 \mathrm{2g}}^{\circ} \\
\mathrm{kcal} / \mathbf{m}\end{array}$ & $\begin{array}{c}\text { c } \\
98^{\circ} \\
\text { cole }\end{array}$ & $\begin{array}{c}\Delta \mathrm{E}_{\mathrm{a}} \\
\mathrm{kcal} / \mathrm{g}-\mathrm{atom}\end{array}$ & $\begin{array}{r}\gamma_{\mathrm{e}} \\
\mathrm{cal} / \mathrm{mole} \\
\times 10 \\
\end{array}$ & -4 & $\begin{array}{c}\mathbf{T}_{\mathbf{m}} \\
{ }^{\mathbf{0}} \mathbf{K}\end{array}$ & \\
\hline $\mathrm{TbB}_{4}$ & $(0.20)$ & (50) & & 135 & $(20.0)$ & & $(2800)$ & \\
\hline $\mathrm{TbB}_{6}$ & $(0.20)$ & $-72^{d}$ & & 144 & $(20.0)$ & & $(2800)$ & \\
\hline $\mathrm{TbB}_{12}$ & $(0.20)$ & (120) & & 139 & $(20.0)$ & & $(2500)$ & \\
\hline $\mathrm{YbB}_{4}$ & $(0.20)$ & (50) & & 124 & (2.8) & & $(2800)$ & \\
\hline $\mathrm{YbB}_{6}$ & $0.170^{d}$ & $-72^{d}$ & & 130 & (2.8) & & (2800) & \\
\hline $\mathrm{YbB}_{12}$ & $(0.20)$ & (120) & & 135 & (2.8) & & $(2500)$ & \\
\hline $\mathrm{YbB}_{100}$ & $(0.20)$ & $(130)$ & & 133 & (2.8) & & $(2270)$ & \\
\hline $\mathrm{LuB}_{2}$ & $(0.24)$ & (30) & & 133 & $(9.0)$ & & $(2500)$ & \\
\hline $\mathrm{LuB}_{4}$ & $(0.20)$ & (50) & & 137 & (21.5) & & $(3000)$ & \\
\hline $\mathrm{LaB}_{6}$ & $(0.20)$ & (72) & & 139 & (21.5) & & $(3000)$ & \\
\hline $\operatorname{LuB}_{12}$ & $(0.20)$ & (120) & & 140 & (21.5) & & $(2500)$ & \\
\hline $\mathrm{B}_{4} \mathrm{C}$ & $0.16 \mathrm{~B}^{\mathrm{k}}$ & 14.0 & (9) & 144 & $(0.03)$ & & 2730 & (2) \\
\hline $\mathrm{SiB}_{4}$ & $(0.20)$ & (15) & & 131 & $(0.0)$ & & 2120 & (2) \\
\hline $\mathrm{SiB}_{6}$ & $0.148^{d}$ & $\sim 20^{d}$ & & 132 & $(0.0)$ & & 2220 & (2) \\
\hline$T$ TB & $0.181^{e}$ & 38.3 & (17) & 142 & (4.1) & & 2460 & (3) \\
\hline $\mathrm{TUB}_{2}$ & $0.240^{\mathrm{d}}$ & 66.8 & (8) & 148 & 2.3 & (32) & 3498 & (3) \\
\hline $\mathrm{ZrB}_{2}$ & $0.237^{d}$ & 73.0 & (8) & 162 & 1.7 & (39) & 3520 & (3) \\
\hline $\mathrm{ZrB}_{12}$ & $(0,20)$ & (120) & & 143 & (8.4) & & 2520 & (3) \\
\hline HfB & $(0.24)$ & (45) & & 163 & $(2.9)$ & & 2370 & (3) \\
\hline $\mathrm{HrB}_{2}$ & $0.242^{d}$ & 80.0 & (8) & 165 & 1.8 & (41) & 3653 & (3) \\
\hline $\mathrm{ThB}_{4}$ & $0.209^{d}$ & $52^{d}$ & & 144 & $(13.4)$ & & $(2800)$ & \\
\hline $\mathrm{ThB}_{6}$ & $0.250^{d}$ & $54.5^{\mathrm{d}}$ & & 144 & (13.4) & & 2470 & (2) \\
\hline$v_{3} B_{2}$ & $0.209^{d}$ & -73 & (54) & 142 & $(6.0)$ & & 2170 & (3) \\
\hline VB & $(0.24)$ & 33.1 & (54) & 144 & $(5.0)$ & & 2840 & (3) \\
\hline & $(0.24)$ & 182.5 & (54) & 145 & (4.5) & & $(2850)$ & \\
\hline & $0.206^{e}$ & 116.3 & (54) & 145 & $(4.3)$ & & 2880 & (3) \\
\hline$v_{2} B_{3}$ & $(0.24)$ & 82.5 & (54) & 145 & $(4.0)$ & & (2950) & \\
\hline $\mathrm{VB}_{2}$ & $0.189^{\mathrm{e}}$ & 48.7 & (54) & 146 & (3.3) & & 3020 & (3) \\
\hline & $0.208^{\mathrm{e}}$ & (70) & & 171 & $(5.4)$ & & 2350 & (3) \\
\hline $\mathbf{M b B}$ & $0.213^{\mathrm{e}}$ & (30) & & 168 & $(4.5)$ & & 3190 & (3) \\
\hline & $0.20 \theta^{\mathrm{e}}$ & $(104)$ & & 165 & (3.9) & & 3210 & (3) \\
\hline & $0.248^{\mathrm{d}}$ & 41.8 & (8) & 160 & 5.8 & (42) & 3910 & (3) \\
\hline & $(0.24)$ & (38) & & 182 & (5.3) & & 2680 & (3) \\
\hline & $0.190^{\mathrm{e}}$ & (73) & & 180 & $(4.8)$ & & 2450 & (3) \\
\hline $\mathrm{TaB}$ & $0.179^{\mathrm{e}}$ & (33) & & 176 & $(4.0)$ & & 3360 & (3) \\
\hline $\mathrm{Ta}_{3} \mathrm{~B}_{4}$ & $0.173^{\mathrm{e}}$ & (120) & & 173 & $(3.4)$ & & 3300 & (3) \\
\hline & $0.200^{\mathrm{e}}$ & 50.0 & (8) & 168 & 4.7 & (32) & 3310 & (3) \\
\hline
\end{tabular}


Table 5 (continued).

\begin{tabular}{|c|c|c|c|c|c|c|c|c|}
\hline \multirow{2}{*}{$\frac{\text { Boride }}{\mathrm{Cr}_{4}{ }^{\mathrm{B}}}$} & \multirow{2}{*}{$\frac{c c_{c}^{b}}{0.284^{e}}$} & \multicolumn{2}{|c|}{$\begin{array}{l}-\Delta \mathrm{H}_{\mathrm{f}, 298^{\circ}} \mathrm{c} \\
\mathrm{kcal} / \mathrm{mole}\end{array}$} & \multirow{2}{*}{$\frac{\Delta \mathrm{E}_{\mathrm{a}}}{\mathrm{kcal} / \mathrm{g} \text {-atom }}$} & \multicolumn{2}{|c|}{$\begin{array}{c}\gamma_{\mathrm{e}^{\prime}} \\
\mathrm{cal} / \mathrm{mole-}^{\circ} \mathrm{K}^{2} \\
\times 10^{-4} \\
\end{array}$} & \multicolumn{2}{|c|}{$\underbrace{T_{\mathbf{K}}}{ }^{\mathbf{m}^{\prime}}$} \\
\hline & & (30) & & & $(3.0)$ & & 1960 & (2) \\
\hline $\mathrm{Cr}_{2} \mathrm{~B}$ & $0.272^{\mathrm{e}}$ & (27) & & 117 & $(2.5)$ & & 2070 & (2) \\
\hline $\mathrm{Cr}_{5} \mathrm{~B}_{3}$ & $(0.24)$ & (75) & & 119 & (2.4) & & 2160 & (2) \\
\hline $\mathrm{CrB}$ & $0.283^{\mathrm{e}}$ & (20) & & 124 & (1.8) & & 2310 & (2) \\
\hline $\mathrm{Cr}_{3} \mathrm{~B}_{4}$ & $0.263^{\mathrm{e}}$ & (75) & & 127 & $(1.6)$ & & 2200 & (2) \\
\hline $\mathrm{CrB}_{2}$ & $0.218^{\mathrm{e}}$ & (33) & & 131 & $(1.3)$ & & 2450 & (2) \\
\hline $\mathrm{CrB}_{6}$ & $(0.20)$ & $(60)$ & & 136 & $(4.6)$ & & $(2400)$ & \\
\hline $\mathrm{MO}_{2} \mathrm{~B}$ & $0.200^{\mathrm{e}}$ & 25.5 & (6) & 158 & (3.3) & & 2550 & (3) \\
\hline MoB & $0.203^{e}$ & 16.3 & (6) & 153 & $(2.5)$ & & 2870 & (3) \\
\hline $\mathrm{MoB}_{2}$ & $0.289^{e}$ & 23 & (6) & 149 & $(1.7)$ & & 2650 & (3) \\
\hline & $0.206^{e}$ & 50 & (6) & 147 & $(1.7)$ & & 2410 & (3) \\
\hline $\mathrm{MoB}_{4}$ & $(0.20)$ & (30) & & 144 & $(6.0)$ & & 2070 & (3) \\
\hline$w_{2} B$ & $0.203^{\mathrm{e}}$ & 23 & (6) & 188 & (1.8) & & 2940 & (3) \\
\hline $\mathbf{W B}$ & $0.219^{d}$ & $-17^{d}$ & & 177 & $(1.4)$ & & 2940 & (3) \\
\hline$w_{2} B_{5}$ & $0.184^{\mathrm{e}}$ & -35 & (6) & 158 & $(1.4)$ & & 2640 & (3) \\
\hline$W_{4}$ & $(0.20)$ & (25) & & 152 & (3.2) & & 2280 & (3) \\
\hline $\mathbf{U B}_{2}$ & $(0.24)$ & 39.3 & (38) & 144 & 22.5 & (38) & 2660 & (2) \\
\hline $\mathrm{UB}_{4}$ & $(0.20)$ & $63^{I}$ & & 144 & (29.5) & 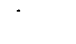 & 2770 & (2) \\
\hline $\mathrm{UB}_{12}$ & $(0.20)$ & $136^{x}$ & & 143 & $(29.5)$ & & 2510 & (2) \\
\hline PuB & $(0.24)$ & (30) & & 124 & (12.5) & & 2320 & (2) \\
\hline $\mathrm{PuB}_{2}$ & $(0.24)$ & (40) & & 130 & (8.3) & & 2100 & (2) \\
\hline $\mathrm{PuB}_{4}$ & $(0.20)$ & (55) & & 134 & (30) & & 2320 & (2) \\
\hline $\operatorname{PuB}_{6}$ & $(0.20)$ & $(60)$ & & 135 & (30) & & 2370 & (2) \\
\hline
\end{tabular}

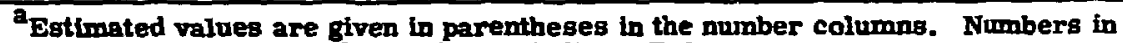
parentheses to the sides of the columns indicate References.

${ }^{\mathrm{B}} \mathrm{C}$ is a parameter that is related to the thermal expansivity by, $a=C \Delta E^{-1} T^{6-4}$. Values of $C$ are derived from existing data given in Table 1 , or from hardness velues using Eq. (11). Eotimates of $C$ are based on Eq8. (8) and (10).

Estimated $\Delta f_{f, 293}^{0}$ values are based on trends in the periodic table.

See Table 1.

Eased on bardness values given by Samsonov."

'pifferences in free enerotes of formation of $\mathrm{UB}_{2}-\mathrm{UB}_{4}$ and $\mathrm{UB}_{4}-\mathrm{UB}_{12}$ were obtained trom Alcock and Grieveson, 35 it was sssumed that these differences vere equivalent to dirierences in $\triangle F F, 298$, and weze combined with the $\triangle F_{1}, 298$ of $\mathrm{UB}_{2}$ (Ref, 3B) to obfain the values for $\mathrm{UB}_{4}$ and $\mathrm{UB}_{12}$ given in the table. 
Table 6. Energy level assignments for lanthanide and actinide fons. ${ }^{a}$

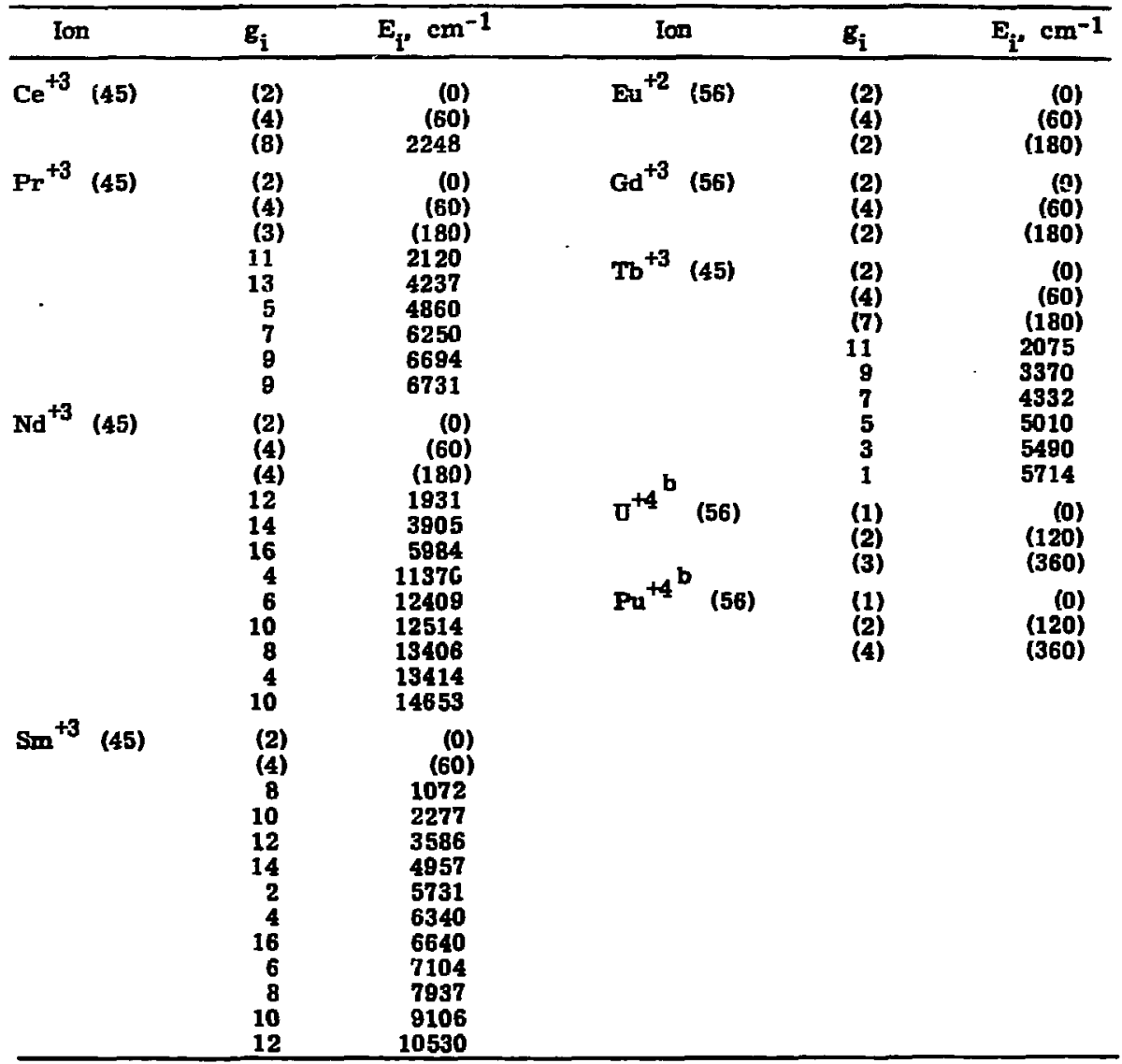

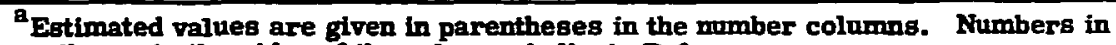
parentheses to the sides of the columns indicate References.

${ }^{b}$ For $U^{+4}$, the ground state is ${ }^{3} \mathrm{E}_{4}, 2 S+1=3,2 J+1=9$, and the multiplicity is assumed to be $1 / 2(2 S+1+2 J+1)=6$. For $\mathrm{Pu}^{\mathrm{f}}$, the ground atate is $\mathrm{5}_{4}, 2 S+1=5$, $2 \mathrm{~J}+1=9$, and the multiplictly is taken to be 7 . 
Table 7. A comparison of calculated and experimental entropies and heat capacities of borides. ${ }^{a}$

\begin{tabular}{|c|c|c|c|c|c|c|c|c|c|c|c|}
\hline \multirow{4}{*}{$\frac{\text { Boride }}{\mathrm{MgB}_{2}}$} & \multirow{2}{*}{\multicolumn{3}{|c|}{$\begin{array}{c}S_{298^{\prime}}^{\circ} \\
\mathrm{cal} / \mathrm{g}-\mathrm{atom}-{ }^{\circ} \mathrm{K} \\
\end{array}$}} & \multicolumn{8}{|c|}{$\mathrm{C}_{\mathrm{p}^{*}}$ cal/g-atom- ${ }^{\circ} \mathrm{K}$, at various tamperatures } \\
\hline & & & & \multicolumn{3}{|c|}{$298^{\circ} \mathrm{K}$} & \multicolumn{3}{|c|}{$1000^{\circ} \mathrm{K}$} & \multicolumn{2}{|c|}{$2000^{\circ} \mathrm{K}$} \\
\hline & \multirow{2}{*}{$\frac{\text { Calc. }}{2.63}$} & \multicolumn{2}{|c|}{ Esper. } & \multirow{2}{*}{$\frac{\text { Calc. }}{3.71}$} & \multicolumn{2}{|c|}{ Exper. } & \multirow[t]{2}{*}{ Calc. } & \multicolumn{2}{|c|}{ Exper. } & \multirow[t]{2}{*}{ Calc. } & Exper. \\
\hline & & 2.87 & (17) & & 3.81 & (17) & & & & & \\
\hline $\mathrm{MgB}_{4}$ & 2.19 & 2.48 & (17) & 3.41 & 3.36 & $(\because 7)$ & & & & & \\
\hline $\operatorname{LaB}_{6}$ & 2.73 & 2.84 & (47) & 3.47 & 3.31 & (47) & 6.13 & 6.02 & (12) & & \\
\hline $\mathrm{NaB}_{6}$ & 3.34 & 3.53 & (47) & 3.50 & 3.38 & (47) & 6.41 & 6.46 & (57) & & \\
\hline $\mathrm{B}_{4} \mathrm{C}$ & 1.24 & 1.30 & (17) & 2.45 & 2.54 & (17) & 5.37 & 5.46 & (17) & 6.39 & $6.70(17)$ \\
\hline $\mathbf{T i B}_{2}$ & 2.45 & 2.27 & (33) & 3.64 & 3.53 & (33) & $5.96^{\circ}$ & 6.00 & (33) & 6.79 & $7.08(33)$ \\
\hline $\mathrm{ZrB} \mathrm{B}_{2}$ & 3.05 & 2.86 & (17) & 3.80 & 3.84 & (17) & 5,93 & 5.75 & (17) & 6.62 & $6.56(17)$ \\
\hline $\mathrm{HFB}_{2}$ & 3.44 & 3.41 & (33) & 3.87 & 3.96 & (33) & 5.94 & 6.41 & (33) & & \\
\hline & 2.88 & 3.05 & (8) & 3.80 & 3.83 & (8) & 6.08 & 6.54 & (B) & & \\
\hline & 3.27 & 3.28 & (32) & 3.86 & 3.82 & (32) & 6.01 & 6.12 & (B) & & \\
\hline $\mathbf{U B}_{\mathbf{2}}$ & 4.97 & 4.42 & (38) & 4.38 & 4.44 & (38) & 6.70 & 7.10 & (58) & & \\
\hline
\end{tabular}

${ }^{\mathbf{a}}$ Reference numbers are given in parentheses. 
Table 8. The enthalpy of melting and the heat capacities of solid and liquid borides.

\begin{tabular}{|c|c|c|c|c|c|c|c|c|c|c|}
\hline \multirow[b]{2}{*}{ Borlde } & \multirow{2}{*}{${ }_{{ }^{\mathbf{m}}}^{\mathbf{T}_{\mathrm{K}}}$} & \multirow{2}{*}{$\begin{array}{l}\text { Ant of } \\
\text { fusion, } \\
\text { cal/ } \\
\text { g-atom }\end{array}$} & \multicolumn{8}{|c|}{$C_{p}$ cal/g-atom-'K, at barious temperatures in ${ }^{\circ} \mathrm{K}$} \\
\hline & & & 298 & 500 & 1000 & 1500 & 2000 & 2500 & 3000 & Liquid \\
\hline $\mathrm{Be}_{4} \mathrm{~B}$ & 1430 & 3289 & 1.793 & 3.618 & 5.525 & 6.419 & 6.419 & 6.419 & 6.419 & 6.418 \\
\hline $\mathrm{Be}_{2}^{3} \mathrm{~B}$ & 1790 & 4117 & 1.989 & 3.779 & 5.552 & 6.413 & 7.253 & 7.253 & 7.253 & 7.253 \\
\hline $\mathrm{BeB}_{2}$ & 3250 & 5175 & 2.480 & 4.188 & 5.657 & 6.229 & 7.153 & 8.112 & 8.112 & 8.112 \\
\hline $\mathrm{BeB}_{6}$ & 2340 & 8792 & 2.760 & 4.417 & 5.700 & 6.152 & 6.782 & 7.819 & 7.819 & 3.810 \\
\hline & 2000 & 7738 & 2.358 & 4.500 & 5.730 & 6.159 & 6.749 & 6.749 & 6.749 & 6.749 \\
\hline & 1300 & 2980 & 3.706 & 5.018 & 6.007 & 6.300 & 6.300 & 6.300 & 6.300 & 6.300 \\
\hline & 1400 & 5124 & 3.410 & 4.643 & 5.680 & 6.237 & 6.237 & 6.237 & 6.237 & 6.237 \\
\hline MgE & 1420 & 5335 & 3.285 & 4.773 & 5.852 & 6.209 & 6.208 & 6.208 & 6.200 & 6.208 \\
\hline $\mathrm{CaB}$ & 2510 & 8430 & 3.349 & 4.803 & 5.865 & 6.270 & B.805 & 8.757 & 8.813 & 8.213 \\
\hline SeB & 2510 & 9430 & 3.396 & 4.825 & 5.883 & 6.294 & 6.938 & $8.78 B$ & 8.854 & 8.854 \\
\hline & 2580 & 9543 & 3.403 & 4.823 & 5.872 & 6.276 & 6.900 & 8.711 & 8.835 & 8.835 \\
\hline & 1250 & 2875 & 3.585 & 4.858 & 5.061 & 8.181 & 6.184 & 6.184 & 6.184 & 6.194 \\
\hline & 2450 & 8480 & 3.113 & 4.673 & 5.780 & 6.159 & 6.687 & 8.052 & 8.052 & 8.052 \\
\hline & 2520 & 5786 & 3.773 & 5.120 & 6.183 & 6.715 & 7.508 & 8.552 & 8.872 & 8.672 \\
\hline & 3000 & 10980 & 3.514 & 5.005 & 8.186 & 6.720 & 7.428 & 8.240 & 12.877 & 12.877 \\
\hline$s$ & 2800 & 8673 & $3,1 \mathrm{B2}$ & 4.757 & 5.838 & 6.381 & 6.861 & 8.500 & 8.540 & 6,500 \\
\hline & 2370 & S451 & 3,913 & 5.156 & 6.156 & 6.637 & 7.351 & 6.576 & 6.574 & 6.575 \\
\hline & 5070 & 11236 & 3,589 & 5.017 & 6,160 & 6.879 & 7,345 & 8.041 & 12,626 & 13.299 \\
\hline & 2870 & 10783 & 3.412 & 4.694 & 6.038 & 6.514 & 7.108 & 8.878 & 11.000 & 11.009 \\
\hline & 2470 & 8557 & 3.209 & 4.757 & $\$ .810$ & 6,350 & 6.689 & 8,249 & 8.243 & 8.249 \\
\hline & 2270 & 8026 & 3.018 & 4.628 & 5.785 & 6.210 & 6.785 & 7.487 & 2.487 & 7.487 \\
\hline & 2070 & 7576 & 3.673 & 5.095 & 6.24 & 6.861 & 7.586 & 7.746 & 2.746 & 3.748 \\
\hline & 2800 & 10520 & 3.472 & 4.952 & 6.132 & 6.654 & 7.285 & 8.923 & 10.744 & 10,744 \\
\hline & 2400 & 6784 & 3.733 & 5.216 & 6.645 & 7.313 & 8.075 & 9.378 & 9.378 & 9.378 \\
\hline & 2510 & 8190 & 3.518 & 5.044 & 6.110 & 7.014 & 7.689 & 8.356 . & 9,416 & 8.416 \\
\hline & 2600 & 9516 & 3.703 & 5.213 & 6.790 & 7.284 & 7.808 & 8.710 & 19.294 & 10.294 \\
\hline & 2700 & 10144 & 3.496 & 5.044 & 6.516 & 6.898 & 7.588 & 9.262 & 10,445 & 10.446 \\
\hline $\mathrm{NdB}_{4}$ & 2800 & 10248 & $3.7 t 6$ & 5.277 & 6.648 & 7.446 & 8.238 & 10.084 & 12.121 & 12.121 \\
\hline $\mathrm{NdB}_{6}$ & 2800 & 10558 & 3.505 & 5.015 & 6.406 & 7.087 & 7.787 & 9.461 & 11.426 & 11.426 \\
\hline & 2600 & 10248 & 3.716 & 5.367 & 6.887 & 7.146 & 7.744 & 9.764 & 11.854 & 11.854 \\
\hline $\sin B$ & 2740 & 10285 & 3.503 & 5.148 & 6.562 & 6.654 & 7.389 & 9.176 & 10.726 & 10.728 \\
\hline & 2520 & 9468 & 3.410 & 4.854 & 5.917 & 8.342 & 7.002 & 8.876 & 8.990 & 8.880 \\
\hline & 2200 & 5060 & 1049 & 5238 & 6.248 & 6.767 & 7.552 & 8.152 & 8.152 & 8.152 \\
\hline $\mathrm{Gag}_{4}$ & 2800 & 10248 & 3.680 & 5.200 & 6.282 & 6.857 & 7.607 & 0.498 & 12.481 & 11.491 \\
\hline $\mathrm{CdB}_{6}$ & 2890 & 20520 & 9.490 & 4.972 & 6.183 & 6.747 & 7.448 & 0.156 & 11.431 & 21,051 \\
\hline & 2270 & ear2 & 3.008 & 4.623 & 5.782 & 6.208 & 6.782 & 7.484 & 7.484 & $7 .+84$ \\
\hline & 2200 & 5080 & 4.081 & 5.379 & 6.729 & 7.238 & T.910 & 8.465 & 8.465 & 8,165 \\
\hline & 2840 & 10248 & 3.704 & 5.175 & 6.553 & 7.114 & 7.787 & 9.546 & 11.502 & 21.502 \\
\hline & 2810 & 10520 & 3.484 & 5.005 & 6.314 & 8.813 & 7.340 & 8.727 & 10.375 & 20.375 \\
\hline TbB & 2500 & 8673 & 3.253 & 4.818 & 6.062 & 8.518 & 7.061 & 0.580 & 8.580 & 8.500 \\
\hline & $28 b 0$ & 10248 & 3.583 & 4.919 & 5.925 & 6.345 & 7,110 & 8.262 & 11.511 & 12.511 \\
\hline & 2800 & 10520 & 3.405 & 4.817 & 5.849 & 6.294 & 6.851 & 8.678 & 10.106 & 10.706 \\
\hline 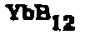 & 2500 & 9573 & 3.206 & 4.718 & 5,818 & 6.217 & 6.771 & 8.402 & 8.402 & B.,102 \\
\hline $\mathbf{Y b B}$ & 2270 & 9042 & 3.003 & 4.615 & 5.775 & E.18A & 6.765 & 7.481 & 7.181 & 7.481 \\
\hline $\operatorname{LaB}_{2}$ & 2500 & 5750 & 3.993 & 5.215 & 6.235 & 6.750 & $7 . \pm 84$ & 9,362 & 0.362 & 8.362 \\
\hline
\end{tabular}


Table 8 (continued).

\begin{tabular}{|c|c|c|c|c|c|c|c|c|c|c|}
\hline \multirow[b]{2}{*}{ Boride } & \multirow{2}{*}{$\mathbf{T}_{\mathbf{r}}}$, & \multirow{2}{*}{$\begin{array}{l}\text { A } \mathrm{H}^{\circ} \text { or } \\
\text { fusiun, } \\
\text { cal! } \\
\text { g-atom }\end{array}$} & \multicolumn{8}{|c|}{ 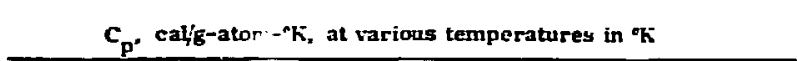 } \\
\hline & & & 298 & 500 & 1000 & 1500 & 2000 & 2500 & 3000 & Liquid \\
\hline $\operatorname{LoB}_{4}$ & 3000 & 10980 & 3.656 & 5.085 & 6.273 & 6.845 & 7.566 & 9.315 & 12.957 & 12.957 \\
\hline $\mathrm{LuB}_{6}$ & 3000 & 11271 & 3.460 & 4.941 & 6.124 & 6.643 & 7.281 & 8.895 & 12.368 & 12.369 \\
\hline LuB & 2500 & 9673 & 3.235 & 4.783 & 5.954 & 6.414 & 6.974 & 8.483 & 8.483 & 8.483 \\
\hline $\mathrm{B}_{4} \mathrm{C}$ & 2730 & 10909 & 2.452 & 3.857 & 5,366 & 5.896 & 6.389 & 7.695 & 8.844 & 8.844 \\
\hline $\mathrm{SLB}_{4}$ & 2120 & 6472 & 3.054 & 4.651 & 5.789 & 6.194 & 6.805 & 7.087 & 7,087 & 7.087 \\
\hline $\mathrm{SIB}_{6}$ & 2220 & 8874 & 3.026 & 4.623 & 5.740 & 6.111 & 6.666 & 7.213 & 7.213 & 7.213 \\
\hline TLB & 2460 & 5658 & 3.997 & 5.207 & 6.110 & 6.514 & 7.040 & 8,306 & 8,306 & 8.306 \\
\hline & 3488 & 8045 & 3.640 & 4.981 & 5.856 & 6.344 & 6.791 & 8.012 & 10.911 & 1 : \\
\hline & 3520 & 8096 & 3.805 & 5,035 & 5.834 & 6.281 & 6.618 & 7.471 & 9.745 & 14.417 \\
\hline ZrB & 2520 & 9750 & 3.179 & +.722 & 5.846 & 6.252 & 6.728 & 8.081 & 8.168 & 8.168 \\
\hline HrB & 2370 & 5451 & 4.336 & 5.323 & 6.095 & $6.4 \pm 8$ & 6.813 & 7.363 & 7.363 & 7.363 \\
\hline & 3653 & 8402 & 3.870 & 5.061 & 5.943 & 6.288 & 6.615 & 7.412 & 9.568 & 15.675 \\
\hline & 2800 & 10248 & 3.617 & 5.006 & 6.108 & 6.591 & 7.155 & 8.578 & 10.244 & 10.244 \\
\hline & 2470 & 9280 & 3.436 & +.899 & 6.038 & 6.521 & 7.079 & 8.369 & 8.969 & 8.369 \\
\hline & 2170 & 4891 & 4.087 & 5.325 & 6.291 & 6.778 & 7.381 & 7.757 & 7.757 & 7.757 \\
\hline & 2810 & 6532 & 3.888 & 5.185 & 6.173 & 6.635 & 7.198 & 8.631 & 10.885 & 10.585 \\
\hline & 2850 & 6555 & 3.798 & 5.120 & 6.113 & 6.557 & 7.081 & 8.469 & 10.444 & 10.444 \\
\hline & 2880 & 6824 & 3.745 & 5.078 & 6.060 & 6.478 & 6.878 & 8.321 & 10.486 & 10.486 \\
\hline & 3850 & 6785 & 3.694 & 5.018 & 6.053 & 6.483 & 6.898 & 8,354 & 11.066 & 11.066 \\
\hline & 3020 & 6896 & 3.562 & 4.949 & 5.945 & 6.328 & 6.776 & 8.039 & 11.049 & 11.208 \\
\hline & 2350 & 5405 & 4.449 & 5.454 & 6.262 & 6.672 & 7.072 & 7.543 & 7.543 & 7.543 \\
\hline $\mathbf{A b}$ & 3180 & $\mathbf{7 3 3 7}$ & 4.189 & 5,289 & 6.134 & 6.517 & 6.888 & 7.689 & 9.786 & 11.109 \\
\hline & 3210 & 7383 & 4.007 & 5.176 & 6.051 & 6.420 & 6.777 & 7,603 & 9.787 & 11.317 \\
\hline & 3310 & 7613 & 3.788 & 5,087 & 6.075 & 6.502 & 6.926 & 7.898 & 10,334 & 12.918 \\
\hline & 2690 & 6187 & 4.776 & 5.615 & 6.340 & 6.748 & 7.143 & 7.816 & 8.287 & 8.287 \\
\hline & 2450 & 5635 & 4.583 & 5.487 & 6.221 & 6.588 & 6.931 & 7.472 & 7.472 & 7.472 \\
\hline $\mathbf{T a}$ & 3360 & 7728 & 4.301 & 5.315 & 6.092 & 6.432 & 6.743 & 7.384 & 8.155 & 11.652 \\
\hline & 3300 & 7590 & 4.102 & 5.186 & 6.008 & 6.336 & 6.630 & 7.286 & 9.131 & 11.192 \\
\hline & 3310 & 7613 & 3.865 & 5.088 & 6.006 & 6.376 & 6.715 & 7.478 & 0.533 & 11.841 \\
\hline & 1960 & 4508 & 4.029 & 5,318 & 8.319 & 6.938 & 8.148 & 8.149 & 8.148 & 8.149 \\
\hline & 2070 & 4761 & 3,841 & 5.177 & 6.179 & 6.709 & 7.762 & 8.017 & 8.017 & 8.017 \\
\hline & 2160 & 4868 & 3.781 & 5.128 & 6.119 & 6.610 & 2.571 & 8.161 & 8.161 & 8.161 \\
\hline CrI & 2810 & 5313 & 3,616 & 5.022 & 6.082 & 6.547 & 7.394 & 8.560 & 8.560 & 8.560 \\
\hline & 2220 & 5106 & 3.519 & 4.951 & 5.995 & 6.450 & 7.204 & 7.891 & 7.891 & 7.891 \\
\hline & 2450 & 5635 & 3.381 & 4.857 & 5.803 & 6.313 & 6.848 & 8.509 & 8.509 & 8.509 \\
\hline & 2400 & go17 & 3.165 & 4.729 & 5.861 & 6.279 & 6.841 & 7.898 & 7,988 & 7.898 \\
\hline & 2550 & 5865 & 4.241 & 5.345 & 6.153 & $6.3 \pm$ & 6.929 & 7.918 & $8,=85$ & 8.085 \\
\hline & 2870 & 6602 & 3.813 & 5.138 & 6.016 & 6.37e & 6.774 & 7.847 & 9.631 & 0.631 \\
\hline & 2853 & 6095 & 3.598 & 1,864 & 5.685 & 6.373 & 6.855 & 8.053 & 8.712 & 6.712 \\
\hline & 2410 & sest & 3.503 & 4,883 & 5.888 & 6.251 & 6.673 & 7.586 & 7.566 & 7.566 \\
\hline & 2070 & 7576 & 3.368 & 4.846 & 5.932 & 6.347 & 6.834 & 6.948 & 6.948 & 6.948 \\
\hline & 2940 & 6762 & 4.439 & 5.383 & 6.051 & 6.3356 & 6.587 & 7.081 & 8.186 & a.196 \\
\hline & 2940 & 6782 & 4.088 & 5.179 & 5.924 & 6.271 & 6.540 & 7,139 & 2.535 & 8.595 \\
\hline$w_{z} B_{5}$ & 2640 & 6072 & 3.587 & 4.926 & 5.866 & 6.200 & 6.529 & 7.434 & 7.817 & 7.917 \\
\hline & 2290 & Bsbi & 3.421 & 4.846 & 5.873 & 6.244 & 6.633 & 7.112 & 7.112 & 7.112 \\
\hline
\end{tabular}


Table $B$ (contimued).

\begin{tabular}{|c|c|c|c|c|c|c|c|c|c|c|}
\hline \multirow[b]{2}{*}{ Boride } & \multirow{2}{*}{$\underset{\boldsymbol{* K}}{\mathbf{T}_{\mathbf{m}}}$} & \multirow{2}{*}{$\begin{array}{l}\Delta \mathrm{H}^{\circ} \text { of } \\
\text { tasion, } \\
\text { cal/ } \\
\text { g-atom }\end{array}$} & \multicolumn{8}{|c|}{ 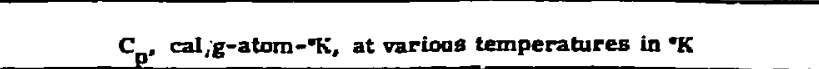 } \\
\hline & & & 298 & 500 & 1000 & 1500 & 2000 & 2500 & 3000 & Liquid \\
\hline $\mathrm{UB}_{2}$ & 2660 & 6118 & 4.375 & 5.540 & 6.695 & 7.394 & 8.204 & 9.884 & 10.766 & 10.766 \\
\hline $\mathbf{U B}_{4}$ & $\mathbf{2 7 7 0}$ & 10138 & 3.853 & 5.226 & 6.440 & 7.069 & 7.784 & 9.360 & 10.908 & 10.908 \\
\hline $\mathrm{UB}_{12}$ & 2510 & 9712 & $\mathbf{3 . 3 1 0}$ & 4.837 & 6.018 & 6.500 & 7.055 & 8.489 & 8.533 & 8.533 \\
\hline PuB & 2320 & 5336 & 5.001 & 5.792 & 6.694 & 7.338 & 8.388 & 9.740 & 9.740 & 9.740 \\
\hline $\mathrm{Put}_{2}$ & 2100 & 1830 & 4.283 & $\mathbf{5 . 3 2 5}$ & 6.249 & 6.743 & 7.511 & 7.779 & 7.779 & 7.778 \\
\hline $\mathrm{PuB}_{4}$ & 2320 & 8491 & 3.885 & 5.244 & 6.466 & 7.120 & 7.965 & 9,024 & 9.024 & 9.024 \\
\hline $\mathrm{PuB}_{6}$ & 2370 & 8904 & 3.624 & 5.059 & 6.265 & 6.845 & 7.596 & 8.790 & 8.780 & 8.790 \\
\hline
\end{tabular}


Table 9. The room temperature entropy and free energy functions of solid and liquid borides.

\begin{tabular}{|c|c|c|c|c|c|c|c|c|c|c|}
\hline \multirow[b]{2}{*}{ Boride } & \multirow{2}{*}{$\begin{array}{c}\mathbf{s}_{29}^{\circ} \\
\text { call } \\
\text { atom- }\end{array}$} & \multicolumn{9}{|c|}{$-\left(F_{T}^{\circ}-E_{20 s}^{\circ}\right), T$, cal/g-aton- ${ }^{\circ} \mathrm{K}$, at various temperatures in $\%$} \\
\hline & & 500 & 1000 & 1500 & 2000 & 2500 & 3000 & 3500 & $\$ 000$ & $T_{m}$ \\
\hline $\mathrm{Be}_{4} \mathrm{~B}$ & 0.775 & 1.049 & 2.454 & 3.964 & 5.751 & 7.148 & 8.295 & 9.268 & 10.112 & 3.669 \\
\hline $\mathrm{Be}_{2} \mathrm{~B}$ & 0.898 & $1.19 i$ & 2.659 & $\$ .086$ & 5.588 & 7.122 & 8.388 & 9.465 & 10.403 & 4.834 \\
\hline $\mathrm{BeB}_{2}$ & $1.20 \mathrm{~B}$ & 1.560 & 3.178 & 4.679 & $\mathbf{5 . 9 5 9}$ & 7.320 & 8.692 & 9.865 & 10.891 & 6.537 \\
\hline $\mathrm{BeB}_{6}$ & 1.386 & 1.769 & 3.473 & 5.013 & 6.305 & 7.667 & 9.261 & 10.586 & 11.721 & 7.080 \\
\hline $\mathrm{BeB}_{12}$ & 1.448 & 1.842 & 3.577 & 5.134 & 6.435 & 8.327 & 9.814 & 11.038 & 12.077 & 6.435 \\
\hline $\mathbf{M g B}_{2}$ & 2.631 & 3.108 & 5.056 & 7.047 & B.925 & 10.370 & 11.544 & 12.534 & 13.389 & 6.105 \\
\hline $\mathrm{MgB}_{4}$ & 2.187 & 2.635 & +.510 & 6.390 & 8.593 & 10.230 & 11.531 & 12.599 & 13.529 & 5.843 \\
\hline $\mathrm{MgB}_{6}$ & 1.996 & 2,433 & +.278 & 6.098 & 8.324 & 9.974 & 11.283 & 12.366 & 13.289 & 5.658 \\
\hline $\mathrm{CaB}_{6}$ & 2.254 & 2.696 & 4.554 & 6.179 & 7.524 & 8.582 & 10.351 & 11.766 & 12.984 & 8.704 \\
\hline $\mathrm{SrB}_{6}$ & 2.664 & 3.110 & 4.979 & 6.610 & 7.960 & 9.123 & 10.797 & 12.215 & 13.438 & 9.145 \\
\hline $\mathrm{EaB}_{6}$ & 2.870 & 3.316 & 5.184 & 6.814 & 8.161 & 9.320 & 10.954 & 12.378 & 13.606 & 9.408 \\
\hline $\mathrm{AN}_{2}$ & 2.321 & 2.787 & 4.709 & 6.760 & 8.601 & 10.019 & 11.172 & 12.141 & 12.984 & 5.583 \\
\hline $\mathrm{AlB}_{12}$ & 1.707 & 2.127 & 3.930 & 5.521 & 6.838 & 8.047 & 9.698 & 11.069 & $12.24 E$ & 7.862 \\
\hline $\mathrm{SeB}_{2}$ & 2.708 & 3.194 & 5.184 & 6.910 & 8.342 & 9.584 & 11.090 & 12.410 & 13.573 & 9.631 \\
\hline $\mathrm{ScB}_{4}$ & 2.298 & 2.760 & 4.701 & 6.408 & 7.830 & 9.062 & 10.195 & 12.822 & 19.275 & 10.195 \\
\hline $\operatorname{SeB}_{12}$ & 1.820 & 2.248 & 4.086 & 5.715 & 7.071 & 8.230 & 0.938 & 11.355 & 12.571 & 8.239 \\
\hline $\mathrm{YB}_{2}$ & 3.401 & 3.898 & 5.805 & 7.631 & 0.057 & 10.107 & 11.876 & 13.230 & 14,224 & 9.980 \\
\hline$Y_{4}$ & 2.702 & 3.170 & 5.118 & 6.822 & 8.241 & 0.465 & 10.587 & 12.131 & 13.592 & 10.741 \\
\hline $\mathrm{YB}_{6}$ & 2.364 & 2.814 & +.710 & 6.377 & 7.762 & 8.854 & 10.206 & 11.756 & 13.116 & 9.765 \\
\hline$Y_{12}$ & 1.975 & $2.4 \mathrm{CS}$ & 4.243 & 5.868 & 7.218 & 8.425 & 10.106 & 11.504 & 12.700 & 8.313 \\
\hline $\mathrm{YB}_{70}$ & 1. EOS & 2.015 & 3.800 & 5.386 & 6.705 & 8.209 & 9.820 & 11.150 & 12.281 & 7.336 \\
\hline $\mathrm{LaB}_{4}$ & 3.215 & 3.692 & 5.673 & 7.409 & 8.859 & 10.739 & 12.339 & 13.667 & 14.801 & 9.044 \\
\hline $\mathrm{LaB}_{6}$ & 2.731 & 3.188 & 5.108 & 6.798 & 8.207 & 0.422 & 10.785 & 12.336 & 13.692 & 10.097 \\
\hline $\mathrm{CeB}_{4}$ & 4.024 & 4.509 & 6.545 & $8 . \hat{558}$ & 9.883 & 11.355 & 13.135 & 14.631 & $15.92 !$ & 10.954 \\
\hline $\mathrm{CeB}_{6}$ & 3.309 & 3.772 & 5.735 & 7.484 & 8.951 & 10.223 & 11.990 & 13.488 & 14.781 & 10.247 \\
\hline $\mathrm{PrB}_{4}$ & 4.037 & 4.519 & 6.562 & 8.397 & 0.932 & 11.255 & 12.948 & 14.508 & 15,862 & 11.504 \\
\hline $\mathrm{PrB}_{6}$ & 3.319 & 3.779 & 5,748 & 7.513 & 8.989 & 10.261 & 11.795 & 13.356 & 14.714 & 10.733 \\
\hline $\mathrm{NdB}_{4}$ & 4.063 & 4.545 & 6.567 & 8.375 & 9.908 & 11.246 & 12.724 & 14.381 & 15.841 & 11.993 \\
\hline $\mathrm{NdB}_{6}$ & 3.337 & 3.798 & 5.749 & 7.494 & 8,966 & 10.244 & 11.655 & 13.267 & 14.680 & 10.978 \\
\hline & 3.889 & 4.377 & 6.474 & 8.345 & 9.888 & 11.209 & 12.664 & 14.301 & 15.743 & i1. 842 \\
\hline $\mathrm{SmB}_{6}$ & 3.212 & 3.677 & 5.680 & 7.466 & B.941 & 10.203 & 11.679 & 13.248 & 14.616 & 10.764 \\
\hline Der & 3.531 & 3.981 & 5.862 & 7.503 & B. 862 & 10,034 & 11.704 & 13.134 & 14.368 & 10.078 \\
\hline & 5.315 & 5.834 & 7.867 & 9.622 & 11.073 & 12.603 & 14.050 & 15.279 & 16,346 & 11.592 \\
\hline $\mathrm{GdB}_{4}$ & 3.870 & 4.348 & 6.331 & B.068 & e.517 & 10.774 & 12.174 & 13.760 & 15.154 & 11.474 \\
\hline $\mathrm{GdB}_{6}$ & 3.201 & 3.659 & 5.589 & 7.290 & 8.712 & 9.944 & 11.325 & 12.897 & 14.273 & 10.629 \\
\hline$G^{2} B_{100}$ & 1.637 & 2.047 & 3.830 & 5.415 & 6.734 & 8.237 & 9.849 & 11.179 & 12.311 & 7.365 \\
\hline & 5.568 & 6.084 & 8.193 & 10.045 & 11.564 & 13.186 & 14.691 & 15.969 & 17.080 & 12.134 \\
\hline $\mathrm{TbB}_{4}$ & 4.017 & 4.498 & 6.516 & 8.308 & 9.806 & 11.101 & 12.531 & 14.140 & 15.553 & 11.820 \\
\hline $\mathrm{TbB}_{6}$ & 3.903 & 3.762 & 5.708 & 7.436 & 8.876 & 10.113 & 11.484 & 19.032 & 14.379 & 10.794 \\
\hline $\mathrm{TbB}_{12}$ & 2.480 & 2.915 & 4.781 & 6.440 & 7.821 & 9.008 & 10.724 & 12.155 & 13.392 & 9.008 \\
\hline & 3.582 & 4.045 & 5.953 & 7.607 & 8..72 & 10.154 & 11.499 & 13.046 & 14,413 & 10.818 \\
\hline $\mathbf{Y b B}_{6}$ & 2.991 & 3.438 & 5.303 & 6.928 & 8.270 & 9.423 & 10.737 & $\mathbf{1 2 . 2 5 2}$ & 13.579 & 10.066 \\
\hline $\mathrm{YbB}_{12}$ & 2.313 & 2.741 & 4.584 & 6,169 & 7.498 & 8.641 & 10.319 & 11.720 & 12.920 & 0.641 \\
\hline $\mathrm{YbB}_{100}$ & 1.622 & 2,032 & 3.811 & 5.392 & 6.707 & 8.208 & 9.817 & 11.146 & 12.276 & 7.336 \\
\hline $\mathbf{L u B}_{2}$ & 3.919 & 4.423 & 6.455 & 8.204 & 9.651 & 10.899 & 12.418 & 13.727 & 14.876 & 10.899 \\
\hline
\end{tabular}


Table 9 (continued).

\begin{tabular}{|c|c|c|c|c|c|c|c|c|c|c|}
\hline \multirow[b]{2}{*}{ Boride } & \multirow{2}{*}{ 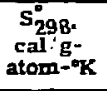 } & \multicolumn{9}{|c|}{$-\left(F_{T}^{\circ}-H_{2 g \beta}^{\circ}\right), T$. cal/g-atom-ak, at various temperatures in ${ }^{\circ} \mathrm{K}$} \\
\hline & & 500 & 1000 & 1500 & 2000 & 2500 & 3000 & 3500 & 4000 & $T_{m}$ \\
\hline $\mathrm{LuB}_{4}$ & 3.032 & 3.507 & 5.483 & 7.216 & 8.663 & 0.915 & 11.065 & 12.704 & 14.165 & 11.065 \\
\hline $\mathrm{LnB}_{6}$ & 2.600 & 3.055 & 4.972 & 6.660 & 8.067 & 9.280 & 10.351 & 12.002 & 13.432 & 10.391 \\
\hline $\mathrm{LuB}_{12}$ & 2.101 & 2.534 & 4.384 & 6.020 & 7.381 & 8.552 & 10.253 & 11.672 & 12.587 & B.552 \\
\hline $\mathrm{B}_{4} \mathrm{C}$ & 1.241 & 1.581 & 3.118 & 4.542 & 5.752 & 6.802 & 8.122 & 9.539 & 10.760 & $7.25 i$ \\
\hline $\mathrm{SiB}_{4}$ & 1.592 & 2.008 & 3.801 & 5.390 & 6.709 & 8.453 & 10.013 & 11.297 & 12.387 & 6.996 \\
\hline $\mathrm{SiB}_{6}$ & 1.570 & 1.982 & 3.764 & 5.341 & 6.647 & 8.218 & 9.801 & 11.104 & 12.211 & 7.159 \\
\hline TiB & 2.941 & 3.447 & 5.472 & 7.198 & 8.614 & 9.858 & 11.313 & 12.551 & 13.628 & 9.729 \\
\hline $\mathrm{T} \mathrm{BB}_{2}$ & 2.450 & 2.921 & 4.853 & 6.520 & 7.891 & 9.058 & 10.108 & 11.122 & 12.442 & 11.117 \\
\hline $\mathrm{ZrB}_{2}$ & 3.051 & 3.536 & 5.492 & 7.164 & 8.532 & 9.688 & 10.712 & 11.679 & 12.922 & 11.717 \\
\hline $\mathrm{Z}_{\Gamma} \mathrm{B}_{12}$ & 1.888 & 2.315 & 4.139 & 5.748 & 7.082 & 8.225 & 9.870 & 11.263 & 12.454 & 8.268 \\
\hline FIB & 4.413 & 4.947 & 7.025 & 8.768 & 10.186 & 11.502 & 12.910 & 14.092 & 15.110 & 11.097 \\
\hline $\mathrm{HrB}_{2}$ & 3.437 & 3.928 & 5.895 & 7.573 & 8.945 & 10.103 & 11.126 & 12.088 & 13.254 & 12.381 \\
\hline $\mathrm{ThB}_{4}$ & 3.113 & 3.582 & 5.526 & 7.221 & 8.527 & 9.834 & 11.173 & 12.685 & 14.005 & 10.458 \\
\hline $\operatorname{ThB}_{6}$ & 2.659 & 3.111 & 5.010 & 6.677 & 8.063 & $\mathbf{9 . 2 9 9}$ & 10.987 & 12,392 & 13.596 & 9.186 \\
\hline$v_{3} B_{2}$ & 2.914 & 3.432 & 5.505 & 7.278 & 8.738 & 10.293 & 11.720 & 12.926 & 13.969 & 9.182 \\
\hline VB & 2.668 & 3.166 & 5.181 & 6.913 & 8.342 & 9.564 & $10.7 \mathrm{gig}$ & 12.147 & 13.351 & 10.324 \\
\hline$v_{5} B_{6}$ & 2.557 & 3.045 & 5.034 & 6.747 & a.159 & 0.366 & 1').573 & 11.912 & 13.103 & 10.137 \\
\hline$v_{3} B_{4}$ & 2.494 & 2.977 & 4.848 & 6.646 & 8.043 & 0.237 & (1).406 & 11.738 & 12.025 & 10.081 \\
\hline & 2.427 & 2.805 & 4.863 & 6.555 & 7.051 & 0,143 & 10.260 & 11.609 & 12.818 & 10.116 \\
\hline & 2.267 & 2.731 & 4.649 & 6.309 & 7.675 & 8.838 & 9.887 & 11.204 & 12.405 & 9.927 \\
\hline & 3.963 & 4.512 & 6.642 & 8.432 & 9.891 & 11.263 & 12.700 & 13.906 & 14.946 & 10.773 \\
\hline $\mathrm{MbB}$ & 3.543 & 4.066 & 6.127 & 7.871 & 0.294 & $10 .+97$ & 11.559 & 12.755 & 13.961 & 11.941 \\
\hline & 3.246 & 3.751 & 5.766 & 7.478 & 8.878 & 10.061 & 11.107 & 12.280 & $13 .+83$ & 11.524 \\
\hline & 2.883 & 3.369 & 5.346 & 7.049 & 8.450 & 9.642 & 10.704 & 11.837 & 13.094 & 11.331 \\
\hline & 5.032 & 5.610 & 7.810 & 9.637 & 11.122 & 12.374 & 13.710 & 14.988 & 16.095 & 12.806 \\
\hline & 4.670 & 5.229 & $7.3 \div 5$ & 9.164 & 10.616 & 11.864 & 13.324 & 14.531 & 15.570 & 11.723 \\
\hline $\mathrm{TaB}$ & 4.133 & 4.664 & 6.738 & 8.479 & 9.894 & 11.085 & 12.128 & 13.187 & 14.393 & 12.827 \\
\hline & 3.752 & 4.264 & 6.288 & 7.997 & 9.389 & 10.559 & 11.586 & 12.672 & 13.857 & 12.163 \\
\hline & 3.269 & 3.760 & 5.738 & 7.430 & 8.816 & 9.987 & 11.021 & 12.115 & 13.324 & 11.625 \\
\hline & 2.660 & 3.173 & 5.242 & 7.018 & 8.544 & 10.285 & 11.720 & 12.940 & 14.000 & 8.387 \\
\hline & 2.459 & 2.953 & 4.963 & 6.695 & 8.132 & 9.777 & 11.197 & 12.403 & 13.451 & 8.316 \\
\hline $\mathrm{Cr}_{5} \mathrm{~B}_{3}$ & 2.397 & 2.885 & 4.875 & 6.590 & 8.009 & 9.556 & 10.984 & 12.200 & 13.258 & 8.419 \\
\hline $\mathrm{CrB}$ & 2.216 & 2.687 & 4.634 & 6.323 & 7.724 & 9.116 & 10.567 & 11.809 & 12.894 & 8.493 \\
\hline $\mathrm{Cr}_{3} \mathrm{~B}_{4}$ & 2.112 & 2.573 & 4.491 & 6.158 & 7.540 & 8.992 & 10.395 & 11.585 & 12.619 & 8.083 \\
\hline & 1.976 & 2.424 & 4.305 & 5.942 & 7.297 & 8.510 & 9.942 & 11.169 & 12.241 & 8.352 \\
\hline & 1.729 & 2.155 & 3.981 & 5.593 & 6.932 & 8.234 & 9.868 & 11.226 & 12.388 & 7.863 \\
\hline $\mathrm{Mo}_{2} \mathrm{~B}$ & 3.205 & 3.735 & 5.817 & 7.571 & 9.001 & 10.210 & 11.624 & 12.860 & 13.932 & 10.922 \\
\hline MoB & 2.772 & 3.270 & 5.266 & 6.967 & 8.357 & 9.535 & 10.686 & 11.979 & 13.121 & 10.321 \\
\hline $\mathrm{MoB}_{2}$ & 2.350 & 2.817 & 4.742 & 6.407 & 7.780 & 8,850 & 10.269 & 11.518 & 12.611 & 9.275 \\
\hline $\mathrm{Mo}_{2} \mathbf{B}_{5}$ & 2.229 & 2.687 & 4.582 & 6.225 & 7.575 & 9.808 & 10,196 & 11.368 & 12.382 & B.529 \\
\hline & 2.042 & 2.487 & 4.363 & 6.005 & 7.364 & 9.153 & 10.665 & 11.912 & 12.971 & 7.536 \\
\hline & 3.805 & 4.350 & 6.451 & 8.196 & 9.605 & 10.783 & 11.854 & 13.130 & 14.182 & 11.650 \\
\hline $\mathbf{w B}$ & 3.228 & 3.738 & 5.754 & 7.453 & 8.834 & 9.993 & 11.053 & 12.300 & 13.388 & 10.891 \\
\hline & 2.496 & 2.962 & 4.871 & 6.515 & 7.862 & 9.002 & 10.287 & 11.487 & 12.529 & 9.295 \\
\hline & 2.214 & 2.664 & 4.539 & 6.172 & 7.517 & 8.969 & 10.530 & 11.814 & 12.905 & 8.200 \\
\hline
\end{tabular}


Table 9 (continued).

\begin{tabular}{|c|c|c|c|c|c|c|c|c|c|c|}
\hline \multirow[b]{2}{*}{ Bortde } & \multirow{2}{*}{$\begin{array}{c}\mathrm{S}_{298} \\
\mathrm{cal} / \mathrm{g}- \\
\text { atom-oK }\end{array}$} & \multicolumn{9}{|c|}{$-\left(F_{T}^{\circ}-H_{298}^{\circ}\right) / T$. cal/g-atom- ${ }^{\circ} K$, at various temperatures in ${ }^{\circ} K$} \\
\hline & & 500 & 1000 & 1500 & 2000 & 2500 & 3000 & 3500 & 4000 & $T_{m}$ \\
\hline $\mathrm{UB}_{2}$ & 4.973 & 5.518 & 7.687 & 9.559 & 11.120 & 12.473 & 13.966 & 15.395 & $1 \varepsilon .662$ & i2.877 \\
\hline $\mathrm{UB}_{4}$ & 3.632 & 4.127 & 6.163 & $\tau .945$ & $\mathbf{9}, \mathbf{4 3 3}$ & 10.722 & 12.177 & 13.760 & 15.142 & 11.365 \\
\hline $\mathrm{UB}_{12}$ & 2.332 & $\varepsilon .773$ & 4.645 & 6.300 & 7.677 & 8.868 & 10.561 & 11.990 & 13.214 & 8.884 \\
\hline PuB & 6.877 & 7.417 & 9.756 & 11.669 & 13.248 & 14.788 & 16.385 & 17.759 & 18.964 & 14.143 \\
\hline $\mathrm{PuB}_{2}$ & 5.050 & 5.579 & 7.661 & 9.430 & 10.887 & 12.507 & 13.926 & 15.125 & 16.164 & 11.151 \\
\hline $\mathrm{PuB}_{4}$ & 5.765 & 4.262 & 6.306 & 8.095 & 9.593 & 11.160 & 12.897 & 14.353 & 15.607 & 10.448 \\
\hline $\mathrm{PuB}_{6}$ & 3.123 & 3.595 & 5.561 & 7.280 & 8.733 & 10.182 & 11.903 & 13.343 & 14.580 & 9.673 \\
\hline
\end{tabular}


Table 10. Enthalpy increments for solid and liquid borides.

\begin{tabular}{|c|c|c|c|c|c|c|c|c|c|c|}
\hline \multirow[b]{2}{*}{ Boride } & \multirow{2}{*}{ 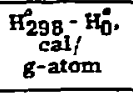 } & \multicolumn{3}{|c|}{$\mathbf{H}_{\mathbf{T}}^{\sigma}-\mathbf{H}_{298}^{0}$} & \multicolumn{5}{|c|}{ cal/g-atom, at vartous temperatures $\ln { }^{\prime} \mathrm{K}$} & \multirow[b]{2}{*}{$T_{m}(\mathbf{s})$} \\
\hline & & 590 & 1000 & 1500 & 2000 & 2500 & 3000 & 3500 & 4000 & \\
\hline $\mathrm{Be}_{4} \mathrm{~B}$ & 166 & 560 & 2942 & 9273 & 12483 & 15693 & 18902 & 22112 & 25322 & $\mathbf{5 5 3 5}$ \\
\hline$B c_{2} \mathrm{~B}$ & 191 & 598 & 3024 & 6010 & 13656 & 17283 & 20910 & 24536 & 28163 & 8016 \\
\hline $\mathrm{BeB}_{2}$ & 254 & 693 & 3238 & 6217 & 9523 & 18665 & 22721 & 26777 & 30833 & 11462 \\
\hline $\mathrm{BeB}_{6}$ & 290 & 747 & 3354 & 6325 & 9533 & 22076 & 25986 & 29895 & 33805 & 12034 \\
\hline $\mathrm{BeB}_{12}$ & 302 & 766 & 3399 & 6380 & 9616 & 20729 & 24103 & 27477 & 30852 & 9616 \\
\hline $\mathrm{MgB}_{2}$ & 495 & 901 & 3712 & 9840 & 12990 & 16140 & 19291 & 22441 & 25591 & 5390 \\
\hline $\mathrm{MgB}_{4}$ & 424 & 855 & 3600 & 11807 & 14825 & 18044 & 21163 & 24281 & 27400 & 6055 \\
\hline $\mathrm{MgB}_{6}$ & 392 & 836 & 3557 & 11957 & 15062 & 18166 & 21271 & 24375 & 37480 & 6125 \\
\hline $\mathrm{CaB}_{6}$ & 424 & 845 & $\mathbf{3 5 7 6}$ & 6615 & 9881 & 13725 & 27605 & 32012 & 36418 & 13857 \\
\hline $\mathrm{S}_{r} \mathrm{~B}_{6}$ & 461 & 851 & 3591 & 6640 & 9920 & 19783 & 27684 & 32111 & 36538 & 13915 \\
\hline $\mathrm{BaB}_{6}$ & 174 & 851 & 3588 & 6631 & 9898 & 13729 & 27780 & 32248 & 36715 & 14127 \\
\hline $\mathrm{AlB}_{2}$ & 452 & 884 & 3672 & 9647 & 12744 & 15841 & 18938 & 22034 & 25131 & 5221 \\
\hline $\mathbf{A l B}_{12}$ & 348 & 810 & 3493 & 6485 & 8673 & 22865 & 26881 & 30817 & 34943 & 12983 \\
\hline $\mathrm{ScB}_{2}$ & 506 & 918 & 3801. & 7032 & 10558 & 14750 & 25429 & 30265 & 35101 & 14980 \\
\hline $\mathrm{ScB}_{4}$ & 440 & 882 & 3742 & 6975 & 10488 & 14588 & 20119 & 37587 & 44076 & 20118 \\
\hline $\mathrm{SeB}_{12}$ & 364 & 825 & 3567 & 6658 & 9977 & 13823 & 27746 & 31896 & 36246 & 13823 \\
\hline $\mathbf{Y B}_{2}$ & 586 & 834 & 3813 & 7015 & 10486 & 20014 & 24302 & 28590 & 32878 & 13448 \\
\hline $\mathrm{YB}_{4}$ & 487 & 889 & 3744 & 6960 & 10444 & 14476 & 17804 & 37732 & 44382 & 20778 \\
\hline $\mathrm{YB}_{6}$ & 438 & 860 & 3857 & 6802 & 10188 & 14072 & 2948 & 35453 & 40957 & 17734 \\
\hline $\mathrm{YB}_{12}$ & 382 & 827 & 3562 & 6635 & 8928 & 23278 & 27388 & 31520 & 35642 & 13473 \\
\hline $\mathrm{YB}_{\mathbf{7 0}}$ & 328 & 796 & 3473 & 6482 & 9707 & 22410 & 26153 & 28497 & 33510 & 11682 \\
\hline $\mathrm{LaB}_{4}$ & 533 & 805 & 3809 & 7101 & 10692 & 22174 & 26047 & 29920 & 33783 & 11267 \\
\hline $\operatorname{LaB}_{6}$ & 471 & 872 & 3706 & 6908 & 10377 & 14367 & 30019 & $\$ 5391$ & 40762 & 17350 \\
\hline $\mathrm{CeB}_{4}$ & 565 & 922 & 3950 & 7451 & 11277 & 24505 & 29194 & 33883 & 38572 & 14783 \\
\hline $\operatorname{Ce}_{6}$ & 491 & 685 & 3814 & 7180 & 10839 & 15042 & 29228 & 33935 & 38643 & 15183 \\
\hline $\mathrm{PrB}_{4}$ & 568 & 916 & 3986 & 7530 & 11302 & 15636 & 30320 & 35467 & 40614 & 16686 \\
\hline $\mathrm{PrB}_{6}$ & 496 & $\mathbf{8 8 1}$ & 3848 & 7240 & 10864 & 15009 & 30305 & 35528 & 10751 & 17027 \\
\hline $\mathrm{NdB}_{4}$ & 571 & 916 & 3927 & 7465 & 11367 & 15882 & 31927 & 37988 & 44048 & 18255 \\
\hline$N \mathrm{~dB}_{6}$ & 498 & 880 & 3785 & 7184 & 10888 & 15135 & 31137 & 36850 & 42563 & 18409 \\
\hline $\operatorname{SmB}_{4}$ & 551 & 835 & 4100 & 7618 & 11303 & 15602 & 31539 & 37516 & 43493 & 18900 \\
\hline $\operatorname{smb}_{6}$ & 484 & 893 & 3913 & 7277 & 10808 & 14876 & 30381 & 35754 & 11117 & 17308 \\
\hline $\mathrm{EnB}_{6}$ & 593 & 858 & 3613 & 6683 & 9991 & 13888 & 27895 & 32390 & 36885 & 14112 \\
\hline $\mathbf{G d B}_{\mathbf{2}}$ & 693 & 954 & 3875 & 7132 & 10683 & 19796 & 23871 & $2 \pi 54$ & 32023 & 12290 \\
\hline $\mathrm{GdB}_{4}$ & 554 & 907 & $3 a 11$ & 7102 & 10695 & 14889 & 30592 & 36308 & 12023 & $1805 B$ \\
\hline $\mathrm{GdB}_{6}$ & 486 & 875 & 3726 & 6965 & 10493 & 14581 & 30378 & 35804 & 41430 & 17648 \\
\hline & $\mathbf{3 2 8}$ & 784 & 3471 & 6478 & $\mathbf{9 7 0 2}$ & 22419 & 26161 & 29903 & 33645 & 11656 \\
\hline & 720 & 869 & 4060 & 7564 & 11923 & 20598 & 24631 & 23083 & 33296 & 12990 \\
\hline & 569 & 814 & 3814 & 7342 & 11045 & 15311 & 31055 & 36806 & 42557 & 18508 \\
\hline & 487 & 878 & 3777 & 7070 & 10593 & 14559 & 30046 & 35284 & 40422 & 17451 \\
\hline & 414 & 697 & 3628 & 6782 & 10158 & 14048 & 28011 & 32301 & 38591 & 14048 \\
\hline $\mathbf{Y b B}_{4}$ & 546 & 878 & 3647 & 6718 & 10047 & 14063 & 29767 & 35523 & 41278 & 17217 \\
\hline $\mathrm{YbB}_{6}$ & 481 & 851 & 3580 & 6207 & 8850 & 13661 & 29265 & 34617 & 38970 & 16603 \\
\hline $\mathbf{Y} \mathbf{b} \mathbf{B}_{\mathbf{1 2}}$ & 405 & 822 & 3524 & 6541 & 9765 & 13534 & 27408 & 31609 & $\mathbf{3 5 8 1 0}$ & I3534 \\
\hline $\mathbf{Y b B}_{100}$ & 928 & 793 & $\mathbf{9 6 3}$ & 6460 & 8673 & 23386 & $261 \pm 7$ & 28867 & 33608 & 11624 \\
\hline $\mathrm{LuB}_{\mathbf{z}}$ & 635 & 87 & 3860 & 7110 & 10843 & 14833 & 25264 & 29845 & S4626 & 14893 \\
\hline
\end{tabular}


Table 10 (continued).

\begin{tabular}{|c|c|c|c|c|c|c|c|c|c|c|}
\hline \multirow[b]{2}{*}{ Boride } & \multirow{2}{*}{$\underset{\text { call }}{\mathbf{H}_{298}-\mathbf{H}_{0}^{*}}$} & \multicolumn{9}{|c|}{$\mathrm{K}_{\mathrm{T}}-11_{208}^{\circ}$, cal $\mathrm{g}$-atom, at various temperatures in " $\mathrm{K}$} \\
\hline & & 500 & 1000 & 1500 & 2000 & 2500 & 3000 & 3500 & $\$ 000$ & $T_{m}(s)$ \\
\hline & 519 & 903 & 3801 & 7087 & 10669 & 14825 & 20369 & 37827 & $\$ 4305$ & 20363 \\
\hline $\mathrm{LBB}_{6}$ & 461 & 870 & 3700 & 6898 & 10360 & 14342 & 19631 & 37087 & $\$ 3272$ & 19631 \\
\hline & 394 & 832 & 3584 & 6684 & 10012 & 13853 & 27773 & 32014 & 26356 & $1585 B$ \\
\hline $\mathrm{B}_{4} \mathrm{C}$ & 259 & 665 & 3067 & 5886 & 8855 & 12420 & 27655 & 32077 & 36499 & 14358 \\
\hline & 330 & 802 & 3483 & 6485 & 9708 & 21741 & 25225 & 28829 & 32372 & 10575 \\
\hline & 326 & 796 & 3459 & 6429 & 9598 & 22048 & 25656 & 29233 & 32870 & 11156 \\
\hline & 551 & 949 & 3827 & 6988 & 10358 & 19875 & 24028 & 28181 & 32334 & 13883 \\
\hline $\mathrm{TiB}_{2}$ & 470 & 891 & 3682 & 6764 & 10034 & 13582 & 18334 & 33116 & 11130 & 25039 \\
\hline & 546 & 811 & 3706 & 6766 & 9984 & 13468 & 17694 & 23578 & 38935 & 23937 \\
\hline & 372 & 821 & 3531 & 6564 & 9783 & 13437 & 27311 & 31395 & 35478 & 13640 \\
\hline HIB & 725 & 990 & 3885 & 7025 & 10334 & 14388 & 23069 & 26751 & 30432 & 12980 \\
\hline & 587 & 920 & 3722 & 6786 & 10006 & 13476 & 17645 & 23406 & 39383 & 25742 \\
\hline & 522 & 890 & 3728 & 6910 & 10331 & 14207 & 29360 & $\mathbf{H 4 8 2}$ & 39604 & 17063 \\
\hline & 163 & 863 & 3860 & 6807 & 10191 & 23318 & 27533 & 31717 & 35902 & 13817 \\
\hline & 552 & 970 & 3922 & 7194 & 10718 & 19583 & 23472 & 27351 & 31209 & 12043 \\
\hline & 511 & 837 & 3828 & 7035 & 10478 & 14378 & 25498 & 31189 & $3 e 408$ & 17671 \\
\hline & 192 & 921 & .3783 & 6957 & 10353 & 14181 & 25041 & S084 & 36086 & 17520 \\
\hline & 182 & 012 & 3752 & 6493 & 10241 & 18010 & 23481 & 30724 & 35967 & 17598 \\
\hline & 170 & 904 & 37ss & 6875 & 10230 & 14012 & 25712 & 31245 & 36778 & 18373 \\
\hline & 143 & 681 & 3864 & 6739 & 10000 & 13649 & 18393 & 30937 & $36 \mathrm{A1}$ & 18811 \\
\hline & 695 & 1016 & 3983 & 7222 & 10653 & 19776 & 29s4t & 27319 & 31091 & 13240 \\
\hline & 630 & 974 & 3874 & 1042 & 10388 & 13889 & 18294 & 31109 & 38684 & 20320 \\
\hline & 584 & 945 & 3801 & 6924 & 10218 & 13776 & 10048 & 30978 & 36636 & 20313 \\
\hline & 528 & 917 & 3761 & 6912 & 10262 & 13927 & I8405 & 32118 & 38577 & 22050 \\
\hline & 82B & 1062 & 4081 & 7357 & 10827 & 145H3 & 24868 & 28011 & 33155 & 16112 \\
\hline & 775 & 1030 & 3093 & 7189 & 10576 & 19846 & 23583 & 27319 & J1055 & 13838 \\
\hline & 697 & 983 & $\mathbf{3 8 8 0}$ & 7016 & 10306 & 13811 & 17078 & 31005 & 36831 & 21846 \\
\hline & G11 & 956 & 3803 & 6898 & 10133 & 13583 & 27817 & 30520 & 36125 & 20701 \\
\hline & 571 & 922 & 3748 & 6850 & 10118 & 13632 & 17811 & 31023 & 36843 & 21160 \\
\hline & 518 & 965 & 3922 & 7230 & 15551 & 18605 & 23680 & 27754 & 31828 & 10697 \\
\hline & 483 & 932 & 3823 & 7044 & 10617 & 18417 & 23425 & 27433 & 31442 & $1120 \theta$ \\
\hline & 472 & 022 & 3787 & 6969 & 10472 & 19511 & 28382 & 27672 & 31752 & 11769 \\
\hline & 410 & 895 & 3722 & 6877 & 10327 & 18764 & 2104 & 20324 & 32605 & 12825 \\
\hline & 122 & 878 & 3674 & 6789 & 20170 & 19180 & 23125 & 22071 & 31016 & 11864 \\
\hline & 398 & 856 & 3608 & 6668 & 0956 & 19486 & 23740 & 279B & 32249 & 13425 \\
\hline & 353 & 821 & 3537 & 6579 & 9837 & 22650 & 26630 & 30629 & $\mathbf{H 6 2 8}$ & 12813 \\
\hline & 598 & 986 & 3804 & 2078 & 10433 & 18102 & 24045 & 26088 & 32130 & 14542 \\
\hline & 526 & 934 & 3773 & 6877 & 10153 & 19762 & 24863 & 29678 & 3494 & 17010 \\
\hline & 456 & 896 & 3676 & 6767 & 10056 & 19726 & 2469 & 28525 & 32:81 & 15025 \\
\hline & 436 & 870 & 3625 & 6866 & 9884 & 18097 & 22820 & 26803 & 30385 & 12813 \\
\hline & 404 & 852 & 3611 & 6888 & 0968 & 21048 & 24522 & 27996 & 31470 & 10485 \\
\hline & 681 & 1008 & 3903 & 7005 & 1024 & 13626 & 3420 & 26037 & $32+35$ & 16988 \\
\hline & 589 & 952 & 3784 & 6848 & 10048 & $1343 B$ & 24157 & 28125 & 32695 & 16843 \\
\hline 5 & 472 & 881 & 3637 & 6661 & 9835 & 13284 & 23318 & 27277 & 31256 & 14396 \\
\hline & 427 & 856 & 3598 & 6635 & 984 & 21740 & 25295 & 28851 & 32407 & 11865 \\
\hline
\end{tabular}


Table 10 (contimed).

\begin{tabular}{|c|c|c|c|c|c|c|c|c|c|c|}
\hline \multirow[b]{2}{*}{ Boride } & \multirow{2}{*}{$\begin{array}{c}\mathbf{H}_{208}^{\prime}-\mathrm{H}_{0}^{\circ} \\
\text { cal: } \\
\mathrm{z}-\mathrm{atom}\end{array}$} & \multicolumn{9}{|c|}{$H_{T}^{\prime}-H_{298,}^{\prime}$ cal/g-atom, al various cemperatures in ${ }^{\circ} K$} \\
\hline & & 500 & 1000 & 1500 & 2000 & 2500 & 3000 & 3500 & 4000 & $\mathbf{T}_{\mathbf{m}}(\mathbf{c})$ \\
\hline $\mathrm{UB}_{2}$ & 762 & 1016 & 4118 & 7645 & 11528 & 15993 & $27+74$ & 32857 & 38240 & 17696 \\
\hline $\mathrm{UB}_{4}$ & $5: 0$ & 835 & 3908 & 7291 & 10988 & 15217 & 30542 & 36096 & 41551 & 17095 \\
\hline $\mathrm{UB}_{12}$ & 422 & 841 & 3625 & 6762 & 1013 & 13962 & 27983 & 32249 & 36316 & 14090 \\
\hline PuB & 1000 & 1098 & 4247 & 7754 & 11650 & 21669 & 26539 & 31408 & 36278 & 14580 \\
\hline $\mathrm{PuB}_{2}$ & 766 & 984 & 3920 & 7171 & $10205^{\circ}$ & 18450 & 24339 & 27229 & 31118 & 11508 \\
\hline $\mathrm{PuB}_{4}$ & 605 & 840 & $38 \approx 2$ & 7324 & 11071 & 23934 & 28446 & 32058 & 37470 & 13818 \\
\hline $\mathrm{PuB}_{6}$ & 523 & 896 & 3787 & 7071 & 10638 & 23755 & 28150 & 32545 & 36990 & 13708 \\
\hline
\end{tabular}

\section{Acknowledgment}

The athor achorledges the generou

ansiotance glven him by Mr. Donald

Jackean, who did the programming and

computer calculatioas for thls work. 


\section{References.}

1. W. B. Pearacon, A Eandbook of Lattice Spacinge and Structures of Metals and Alloge (Pergamon Press, New York, 1858). Bid., Vol. 2 (1867).

2. M. Ennsen and $K$. Anderko, Conatitution of Binary Alloys (McGrap-Rill Book Co., New York, 1858).

R. P. Ellot, Conothtution of Binary Allors, First Supplement McGraw-Hill Book Co., New York, 1965).

F.A. Shmik, Constitution of Binery Alloge, Second Supplement (McGram-Hill Book Co., New York, 1969).

3. E. Fudy. Tornary Fuase Equilibrin in Trnoftion Metal-Boron-Carban-Silicon Sratems. Fart V. Compendim of Fuane Diarram Dats, Afr Force Mnterials Laboratory Report ARMI-TR-65-2, Part V (AD-689843) (May 1968): U. S. Dept. of Commerce Clearinghouse for Federal Sclentific and Techaical Information, Springiteld, Virginin.

4. G.V. Samsonov, Plenum Pregs Bindibooks of Hifh-Temperature Materinis. Sio. 2 - Propertice Index (Plenum Pres:, New Yort, 1964).

8. J.A. Formma, A. Fablin, K.J. Taner, and R.J. Welea, J. Fing. Chem. Sollda 1. 45 (1986).

6. Thermoghvalcal Properties of Fith Temparature Solid Materinls, Vols. 1-6, Y.S. Touloulian, Ed. (MneMulun Co., New York, 1967).

7. L. Brewer and H. Finaldsen, J. Electrochem. Soc, 102, 399 (1955).

8. H. L. Schlck, Thermodrmamics al Certain Rofractory Compounds, Vols. 1 and 2, (Academic Press, New York, 1966).

9. O. KubasechewakL E.L. Evans, and C. B. Alcock, Metallardical Thermochemistry (Pergamon Press, Ouford, 1967), th ed.

10. S. Aronson and A. Aukerm, "The Free Dereies of Formation of Thorium Borides from Measurements on Solid EMF Cells," in Thermodyamics, Vol. I (interntiouel Atomlc Brersy Agency, Vienn, 1966).

11. J.M. Lelthaker, N. H. Krikorinn, and M, B. Borman, "High Temperatare Poisons," Symposium on Rocent Developments in Materials for Nuclear Appiicathas, American Society for Metals, Albuquerque, New Mexico, Feb., 1961; clted by P.K. Smith in Lnthnide Eoride Sratems and Propexties. Part I: Lanthanide-Boran-Carton Sruteme. Part II: Vaporization and Siabilities of Lanthantile Borides, Ph. D. Thesle, University of Kansas, Lawrencs, Kansas (Ming, 1864).

12. G. V. Samsonov and Y. B. Paderno, Borides of the Rare Earth Metals (PublishIn House of the Academy of Sciences, Uarainian SSR, Kiev, 1961; English trenglation, AEC-tr-5264, Oct., 1962, Office of Technical Services, Dept. of Commerce, Washington, D.C.).

G. V. Samsonov, Eigh-Temperature Compounds of Rare Earth Metals with Fonmetals (Consultants Bureau, New York, 1865). 
13. E. K. Storms, The Refractory Carbides (Academic Press, New York, 1967).

14. W. B. Wilson, J. Amer. Ceram. Soc. 43, 77 (1960).

15. C. P. Kempter and R. O. Elliott, J. Chem. Phys. 30, 1524 (1959).

18. R. E. Honig and D.A. Kramer, "Vapor Pressure Data for the Solid and Liquid Elements," RCA Rev. 30, 285 (1969).

17. JANAF Thermochemical Tables, through Supplement No. 33, June 30, 1970 (The Dow Chemical Company, Midland, Michigan).

18. J. F. Lynch, C. G. Ruderer, and W. E. Duckworth, Engineering Properties of Selected Ceramic Materials (Amexican Ceramic Society, Columbus, Ohio, 1966).

19. S. P. Clark, Jr., Fandbook of Phrsical Constants (The Geological Society of America, New York, 1966), revised ed.

20. D. E. Whey, W. R. Manning, and O. Funter, Jr., J. Less-Common Metals 18, 149 (1969).

21. P. T. B. Shaffer, Plenum Press Eandbooks of High-Temperature Materials. No. 1 - Materials Index (Plemum Press, New York, 1964).

22. L. J. Graham and R. Chang. "The Flastic Properties of Uranium Carbide Between 4.2 and $300^{\circ} \mathrm{K}$," in Compounds of Interest in Nuclear Reactor Technology, J. T. Waber and P. Chlotti, Eds. (American Institute of Mining, Metallurgical and Petroleum Engineers, 1964).

23. H. L. Whaley, W. Fulkerson, and R.A. Potter, J. Nucl. Mater. 31, 345 (1969).

24. N. Soga, J. Amer. Ceram. Soc. 52, 246 (1869).

25. K. K. Kelley and E. G. King, Contributions to the Data on Theoretical Metallurgg. XIV. Entropies of the Elements and Inorganic Compounds, Bureau of Mines Bulletin 592 (U.S. Govermment Printing Office, Washington, 1961).

26. E. F. Westram, Jr., and C. M. Barber, J. Chem. Phys, 45, 635 (1866).

27. K.A. Gachneidner, Jr., Rare Earth Alloys (D. Van Nostrand Co., Princeton, New Jersey, 1961).

28. W. R. Mamning and O. Hunter, Jr., J. Amer. Ceram. Soc. 52, 492 (1969).

W. R. Maming and O. Funter, Jr., J. Amer. Ceram. Soc. 53, 279 (1969).

29. N. Soga and O. L. Anderson, J. Amer. Ceram. Soc. 49, 355 (1966).

30. O. J. Keppa, J. Chem. Phys, 18, 1331 (1950).

31. H. P. Kirchner, "The Thermal Expansion of Ceramic Crystals," in Progress in Solid State Chemistry Vol. 1, E. Reiss, Ed. (MacMillan Co., New York, 1964), p. 8.

32. L. Kaufman, Investigation of Boxide Compounds for Very High Temperature Applications, Technical Documentary Report No. RTD-TDR-63-4096, Part I, Office of Tectmical Serrices, U.S. Dept. of Commerce, Washington, D.C. (December, 1963).

33. R. Finltgren, R. L. Orr, F.D. Ardergon, and K. K. Kelley, Selected Values of Thermodyamic Properties of uetais and Alloys (John Wiley and Sons, New York, 1963). Loose Leaf Supplements through June, 1870. 
34. C. Kittel, Introduction to Solid State Physics (Wiley and Sons, New York, 1968), 3 rd ed.

35. W. C. Overton, Jr., J. Chem. Phys. 37, 2975 (1962).

36. R. Kuentzler, Compt. Rend., Ser. B, Sci. Phys. 270, 197 (1970).

37. B. T. Matthias, T.H. Geballe, K. Andres, E. Corenzwit, G. W. Hull, and J.P. Maita, Science 159,530 (1968).

38. H. E. Flotow, D.W. Osborne, P.A.G. O'Hare, J. L. Settle, F. C. Mrazek, and W. N. Hubbard, J. Chem. Phys. 51, 583 (1969).

39. E. F. Westrum, Jr., and G. Feick, J. Chem. Fng. Data 8, 193 (1963).

40. J.P. Mercurio, J. Etournean, R. Naslain, and J. Bonnerot, C. R. Acad. Sci. Piris Ser. 268B, 1766 (1969).

41. E. F. Westrum, Jr., Thermodynamic and Kinetic Studies for a Refractory Materials Program, Technical Documentary Report No. ASD-TR-62-204, Part III, Office of Technical Services, U.S. Dept. of Commerce, Washington, D.C. (August, 1963).

42. E. F. Westrum, Jr., and G.A. Clay, J. Phys. Chem. 67, 2385 (1963).

43. D. O. Ven Ostenburg, D. J. Lam, M. Shimizu, and A. Kateukd, J. Phyg, Soc. Japan 18, 1744 (1963).

44. E. F. Westrum, Jr., and F. Gronvold, Thermodynamics of Nuclear Materials (International Atomic Energy Agency, Vienna, 1862).

45. D. H. Dennison and K. A. Gschneidner, A Tabulation of the Specific Heat Comtribution due to Thermal Brcitation (Schotticy Effect) of the if Electrons of Some Di- and Tri-Valent Lanthanide Elements, Ames Laboratory Report IS-1156, Ames Laboratory, Iowa State University of Science and Technology (May, 1965).

46. E. F. Westrum, Jr., and W. G. Lyon, "Thermodynamics of Semi-Metallic Compounds," in Thermodynamics of Nuclear Materials, 1967 (International Atomic Energy Agency, Vienna, 1968).

47. E. F. Westrum, Jr., H. L. Clever, J. T.S. Andrews, and G. Feick, "Thermodynamics of Lanthanum and Neodymium Hexaboride," in Rare Earth Research, L. Eyring, Ed. (Gordon and Breach, New York, 1964).

48. E. F. Westrum, Jr., J. T.S. Andrews, and G. A. Clay, Thermal Anomalies and Thermodynamic Properties of Gadolinium Hexaboride, Fifth Rare Earth Research Conference, August 30-Sept. 1, 1965, AD-627224, U.S. Dept. of Commerce Clearing House tor Federal Scientific and Technical Information, Springfield, Virginia.

49. P. G. Shewmon, Diffusion in Solids (McGraw-Hill, New York, 1963 ).

50. Y.A. Kraftmakher and P.G. Strelkov, Soviet Physics-Solid State B, 839 (1966). Y.A. Kraftmakher, ibid., 9, 1458 (1967).

Y.A. Krattmakher, ibid., 9, 1197 (1967).

51. G. H. Winslow and R. J. Thorn, High Temp. Sci. 1, 128 (1969).

52. R. A. Swalin, Thermodynamics, Vol. II (International Atomic Energy Agency, Vienna, 1966). 
53. I.A. Stegun, Handbook of Mathematical Functions win Formulas, Graphs, and Mathematical Tableg, M. Abramowitz and I. A. Stegun, Eds. (U. S. Dept. of Commerce, National Bureau of Standards, Waghington, D. C., 1964), p. 998.

54. K. E. Spear, H. Schäfer, and P.W. Gilles, "Thermodynamies of the Vanadium Borides," in High Temperature Technology, Butterworth and Compaty, Landon, 1969.

55. C. Alcock, and P. Grieveson, "Study of Uraninm Borides and Carbides," in Thermodynamics of Nuclear Materials, (International Atomic Brergy Agency. Viemna, 1962).

56. B. G. Wybourne, Spectroscoplc Properties of Rare Earths (Interscience Publishers, New York, 1965).

57. V.N. Prilepaki, E.N. Timsteeva, V.A. Timofeev, and A.Y. Trubitayn, Isv. Akad. Nauk SSSR, Neorgan, Mater. 6. 2069 (1920).

58. D. R. Fredrickson, R.D. Barnes, M. G. Chasanov, R. L. Kuttall, R. Kleb, and W. N. Eubbard, High Temp. Scl. 1, 373 (1968). 